\title{
Emission Rates of Volatile Organic Compounds Released from Newly Produced Household Furniture Products Using a Large-Scale Chamber Testing Method
}

\author{
Duy Xuan Ho, ${ }^{1}$ Ki-Hyun Kim, ${ }^{1}$ Jong Ryeul Sohn, ${ }^{2}$ Youn Hee Oh, ${ }^{2}$ and Ji-Won Ahn ${ }^{1}$ \\ ${ }^{1}$ Department of Environment \& Energy, Sejong University, \\ Seoul 143-747, Republic of Korea \\ ${ }^{2}$ Department of Environmental Health, Korea University, \\ Seoul 136-075, Republic of Korea
}

Received 7 May 2011; Revised 12 August 2011; Accepted 12 August 2011

Academic Editor: Richard Brown

The emission rates of volatile organic compounds (VOCs) were measured to investigate the emission characteristics of five types of common furniture products using a $5 \mathrm{~m}^{3}$ size chamber at $25^{\circ} \mathrm{C}$ and $50 \%$ humidity. The results indicated that toluene and $\alpha$-pinene are the most dominant components. The emission rates of individual components decreased constantly through time, approaching the equilibrium emission level. The relative ordering of their emission rates, if assessed in terms of total VOC (TVOC), can be arranged as follows: dining table $>$ sofa $>$ desk chair $>$ bedside table $>$ cabinet. If the emission rates of VOCs are examined between different chemical groups, they can also be arranged in the following order: aromatic (AR) $>$ terpenes (TER) $>$ carbonyl $(\mathrm{CBN})>$ others $>$ paraffin $(\mathrm{PR})>$ olefin $(\mathrm{HOL})>$ halogenated paraffin $(\mathrm{HPR})$. In addition, if emission strengths are compared between coated and uncoated furniture, there is no significant difference in terms of emission magnitude. Our results indicate that the emission characteristics of VOC are greatly distinguished between different furniture products in terms of relative dominance between different chemicals.

KEYWORDS: volatile organic compounds (VOCs), total volatile organic compound (TVOC), furniture products, chamber test, emission rate, health hazard 


\section{INTRODUCTION}

Volatile organic compounds (VOCs) have received a great deal of attention due to high abundances and associated impact on health, especially in indoor environments [1,2]. A wide spectrum of sources can contribute to the emission of VOCs in both indoor and outdoor environments. In case of indoor emission, VOCs are released from furnishing products and/or household products. Although the chemical compositions of VOCs in the indoor environment are not simple enough to describe, aromatic hydrocarbons have often been identified as the most dominant components [3,4]. A number of compounds such as benzene, toluene, ethyl benzene, and xylene are widely known as the key components with common grouping acronyms like BTEX $[5,6]$.

The emission rates of VOC have been measured intensively by numerous authors to help to assess their influence on air quality and the human health impact [7,8]. Chamber method is one of the common testing techniques to evaluate the exchange rate of such pollutants released from diverse sources. As VOCs can be produced from various materials used in residential households (such as wood-based products, adhesives, rubber, and wall paint), they can affect human health to varying degrees [9]. The pattern of VOC emissions, if assessed between source materials or between chemical components, can vary greatly between materials under diverse conditions $[10,11]$. Frequent usage of certain furniture products in every normal day may increase the rate of exposure to reactive substances and secondary products released or produced in indoor air [12]. This type of exposure can lead to many common symptoms, for example, acute respiratory infections, lung disease, allergies, and so forth [13-16].

To learn more about the emission characteristics of indoor VOCs from household sources, five types of furnishing products (i.e., desk chair, bedside table, dining table, sofa, and cabinet) were chosen to explore the basic aspects of the indoor emissions. Emission rates of all these 5 products were measured by employing a large-scale chamber system. The results of our chamber experiments were evaluated in terms of their exiting concentration $\left(\mu \mathrm{g} / \mathrm{m}^{3}\right)$ levels and emission rate estimates (flux in terms of $\mathrm{mg} / \mathrm{unit} / \mathrm{hr}$ ) for direct comparison between different parameters.

\section{MATERIALS AND METHODS}

\subsection{Overview of Sampling Chamber}

In this study, a big-size chamber system with a $5 \mathrm{~m}^{3}$ capacity was used to collect samples from each of our 5 target furniture products. The chamber system basically consists of 4 parts: the main emission chamber, air purification system, temperature (and humidity) control system, and heating unit (Figure 1). The main emission chamber is built with a double body structure, which includes (1) an inner chamber (width $1.850 \times$ depth $1.850 \times$ height $1.500 \mathrm{~mm}$ ) and (2) an outer chamber (width $4.000 \times$ depth $2.500 \times$ height $2.400 \mathrm{~mm}$ ). The inner unit was made using SUS 304 material (stainless steel) to minimize adsorption of pollutants. The edge of chamber doors was coated with Teflon material to protect gas leaking with inertness. In addition, to reduce possible contamination during sample collection, we employed an air purification system consisting of a prefilter unit, a molecular sieve (10 ̊) filter (for dehumidification), and a main filter made of microactivated charcoal $\left(1300 \mathrm{~m}^{2} / \mathrm{g}\right)$. The air trapped between the two (inner and outer) chambers was heated constantly by the heating unit at $70^{\circ} \mathrm{C}$.

\subsection{Testing Materials (Furniture Products)}

In this study, 5 different furniture product samples (in low to middle price range) commonly available in republic of Korea were selected by considering popularity, variety, and communality. All of these samples were purchased less than 2 weeks of their arrival at the end seller. The selected samples can be described as follows. 


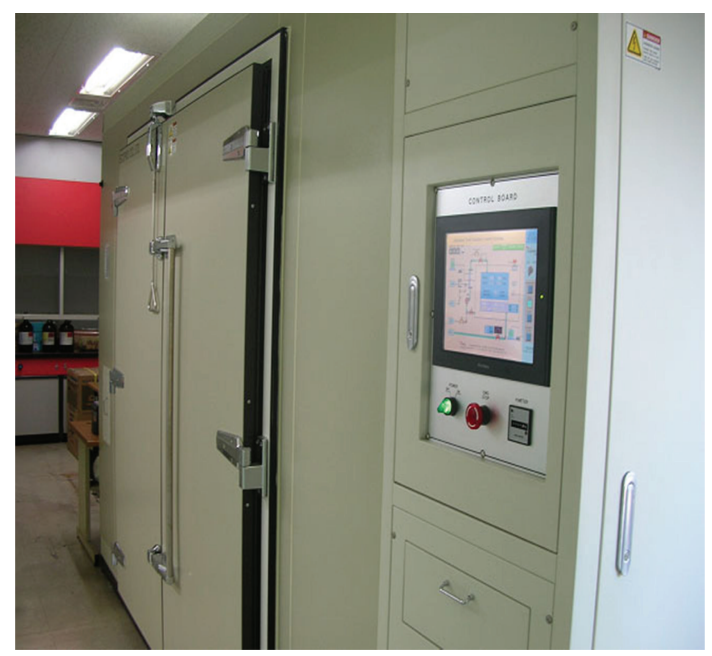

FIGURE 1: Emission test chamber system, $5 \mathrm{~m}^{3}$ in size (Ecopro, Republic of Korea).

(1) Table and chair (medium density fiberboard (MDF) 100\%).

(2) Bedside table made of board (MDF (50\%), high-density fiberboard (HDF: 20\%), and particleboard (PB: 30\%). Its surface is covered with low-pressure melamine (LPM: 80\%) and polyvinyl chloride (PVC: 20\%).

(3) Dining table (natural marble (50\%), rubber wood (40\%), and MDF (10\%)) with chair (wood (30\%), MDF (10\%), foam (20\%), and polyurethane (PU) leather (40\%)).

(4) Sofa with foam (20\%) and PU leather (80\%).

(5) Cabinet made up of board (PB (70\%) and MDF (30\%)) with its surface (LPM (70\%) and polypropylene (PP: 30\%)).

\subsection{Sampling}

The chamber test for each furniture product was technically undertaken as the 2-stage test from blank to real samples (Figure 2). The former step was initially taken to check the cleanness and stability of the system, as the maintenance of the blank level is quite critical to operate this chamber system. Once this initial step is completed, the latter step proceeded to estimate the emission rates of the actual samples. The emission rates of all 5 target products were measured during the period of 28 August through 27 December 2009.

\subsubsection{Cleaning and Bake-Out for Blank Level Analysis}

It is important to reduce any possible bias in the measurements of emission rates for diverse furniture types. Thus, recovery rate of chamber was first tested for blank conditions of chamber. To initiate the blank experiments, it was first cleaned using (1) ethanol and (2) pure water. It was then baked at $70^{\circ} \mathrm{C}$ for 24 hours and stabilized at $25^{\circ} \mathrm{C}$ and $50 \%$ relative humidity (RH). Pure air was supplied constantly into the chamber for a duration of 24 72 hours to check the blank levels of the flux measurements. Then, the air sample was loaded into sampling tube filled with Tenax-TA (Supelco, USA) adsorbent for 30 minutes at a flow rate of $0.15 \mathrm{~L} \mathrm{~min}^{-1}$. Once samples are collected, each tube was protected immediately from contamination by the use of air tight tube seal. The collected sampling tube was analyzed for VOC by gas chromatography/mass spectrometer (GC/MS) system (Agilent 6890, USA) combined with thermal desorber (Model: TDS2-7, 


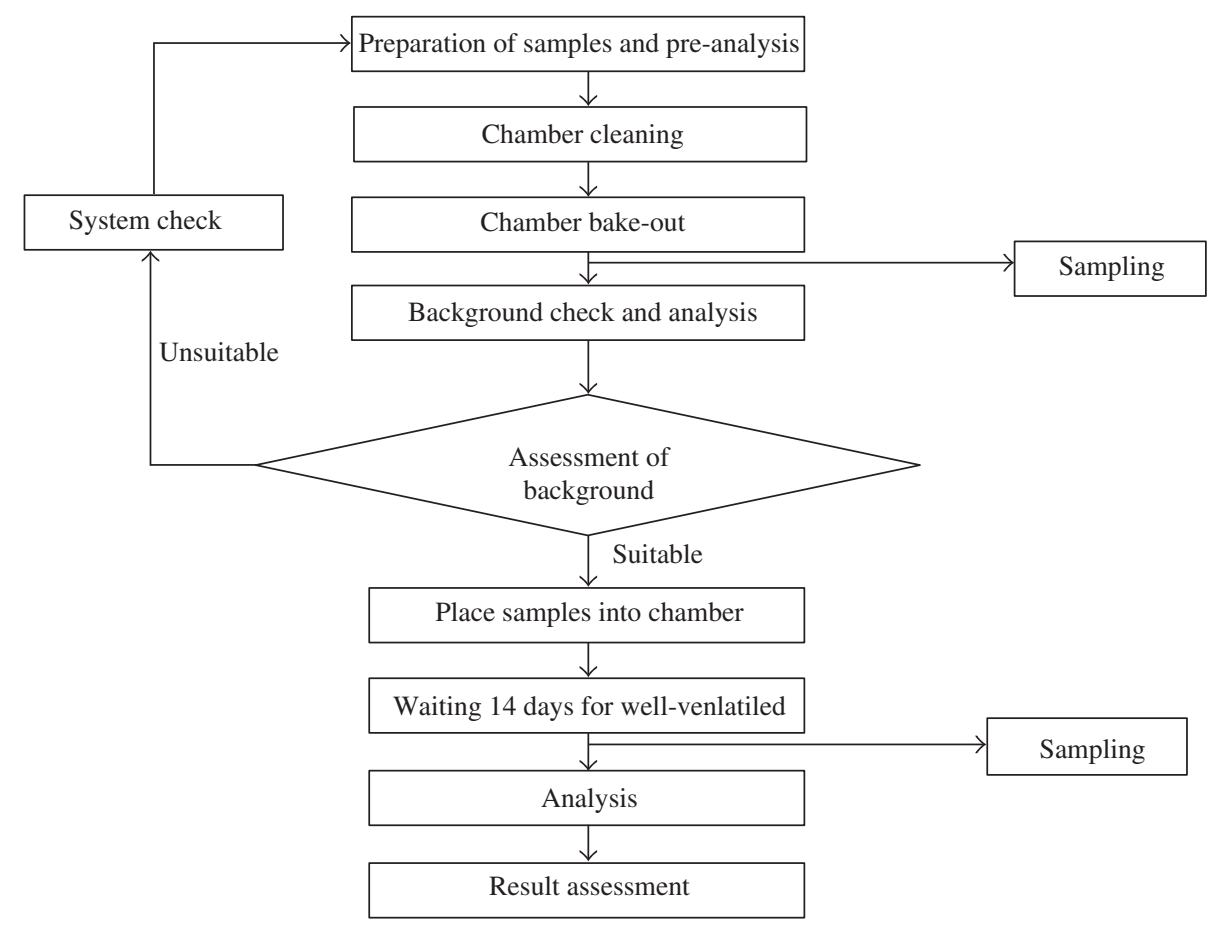

FIGURE 2: Flowchart of the chamber emission test procedure.

Gerstel, Germany). If the blank values of TVOC were above $20 \mu \mathrm{g} \mathrm{m}^{-3}$, chamber cleaning was repeated with a replacement of the filter units.

\subsubsection{Sample Test}

After a blank test, the emission rates of each furniture type were measured by following the chamber test procedure established by the Korea National Institute of Environmental Research (NIER). To this end, upon unpacking, our target sample was placed inside the chamber at the center position. The drawers (or the doors) in the samples were left open during emission test. Throughout the tests, the temperature and humidity were maintained constantly at $25 \pm 1{ }^{\circ} \mathrm{C}$ and $50 \pm 5 \%$, respectively. Exiting air was ventilated at a frequency of 0.5 times per hour. The sample loading rate $(L)$ is an important factor determined by the ratio between surface area and volume of chamber $\left(\mathrm{m}^{2} / \mathrm{m}^{3}=1 / \mathrm{m}\right)$. The loading factor $\left(\mathrm{m}^{2} / \mathrm{m}^{3}\right)$ of all target samples was set to fall in the range of $0.4 \leq L \leq 1$. The emission rates of the target samples were measured for a total period of 2 weeks ( \pm 3 days) at intervals set arbitrarily as of 2, 4, and 8 hours and 1, 2, 3, 4, 7, 10, and 14 days.

\subsection{Analysis of VOC and QA}

The equipment and the procedure employed for the determination of VOCs are described below. The operation conditions for GC/MS and thermal desorber (TD) system are described in Table 1. Results of the TD recovery tests using a list of VOCs (benzene, toluene, ethylbenzene, m,p-xylene, styrene, o-xylene, and $\mathrm{n}$-dodecane) were computed as $93 \sim 108 \%$. The concentration of TVOC was calculated by integrating all individual VOCs from n-hexane to n-hexadecane. The liquid-phase primary standard for VOCs (Japanese indoor air standards mix, Supelco, USA) was used to prepare a working standard (WS) at 5 concentration levels $(20,50,100,200$, and $500 \mathrm{ng})$. These WSs were routinely injected into the sampling tube filled with 
TABLE 1: Operating conditions of TD and GC/MS system for the analysis of VOC.

\begin{tabular}{lc}
\hline Parameter & Conditions \\
\hline (A) Thermal desorber (TD) & $325^{\circ} \mathrm{C}$ \\
Desorption temperature & $30 \mathrm{~mL} / \mathrm{min}, 15 \mathrm{~min}$ \\
Desorption flow rate and time & Liquid $\mathrm{N}_{2}$ or adsorber \\
Cold trap material & $-50^{\circ} \mathrm{C}$ \\
Cold trap temperature & \\
\hline (B) GC/MS system & $300^{\circ} \mathrm{C}$ \\
Injector temperature & $\mathrm{He}$ \\
Carrier gas & $\mathrm{DB}-1$ capillary column \\
GC column & $(0.32 \mathrm{~mm}, 60 \mathrm{~m}, 1 \mu \mathrm{m})$ \\
Column flow rate & $1.2 \mathrm{~mL} / \mathrm{min}$ \\
Temperature program & $40^{\circ} \mathrm{C}(5 \mathrm{~min})-4{ }^{\circ} \mathrm{C} / \mathrm{min}\left(180^{\circ} \mathrm{C}\right)-$ \\
MS source temperature & $20^{\circ} \mathrm{C} / \mathrm{min}\left(250^{\circ} \mathrm{C}\right)-250^{\circ} \mathrm{C}(10 \mathrm{~min})$ \\
Detector type & $250^{\circ} \mathrm{C}$ \\
Mass range & Electron impact ionization \\
Electron energy & $35 \sim 350$ amu \\
\hline
\end{tabular}

Tenax TA. In our analysis of VOCs, there are a number of limiting factors to derive fully quantitative data sets. For instance, although the use of Tenax is potent enough to assess concentration levels of common VOCs (e.g., BTEX), it is not necessarily compatible with all individual components of PS, especially the lighter VOCs (e.g., 1,1,1-trichloroethane (ISO 16017-1)). For the analysis of samples, a total sampling volume of $4.5 \mathrm{~L}$ was collected at a flow rate of $0.15 \mathrm{~L} / \mathrm{min}$ for 30 minutes (MP-30 pump, Sibata, Japan). Before sampling, the adsorption tube was conditioned for 240 minutes at $300^{\circ} \mathrm{C}$ with the supply of pure $\mathrm{N}_{2}(150 \mathrm{~mL} / \mathrm{min})$ using tube conditioner (APK1200, KNR, Korea). After sampling, the tubes were stored in an airtight condition below $4^{\circ} \mathrm{C}$ and analyzed within 2 weeks. The method detection limit (MDL) was estimated by seven repetitive analyses of the least detectable quantity of working standard loaded into the sampling tube. The MDL values for each compound estimated in terms of absolute mass were typically under $2 \mathrm{ng}$. In addition, the relative standard deviation for all target VOCs, if derived based on three repetitive analyses of the sampling tube, fell below $5 \%$.

\section{RESULTS AND DISCUSSIONS}

\subsection{Estimate of VOC Emission Rate}

The emission rates for the materials are estimated by considering a particular flow of air passing through the unit in the test chamber $(\mathrm{mg} / \mathrm{unit} / \mathrm{h})$. The VOC emission rates for the test materials are thus determined in parallel by concentration $\left(\mu \mathrm{g} / \mathrm{m}^{3}\right)$ of each target component exiting the chamber. Information on the amount of VOCs contained in the exiting air $\left(\mu \mathrm{g} / \mathrm{m}^{3}\right)$ provides us with general information of VOC levels and the following exchange rates through time:

$$
\mathrm{SER}_{\mathrm{u}}=\frac{\left(C_{t}-C_{t b}\right) \times Q}{1 \text { unit }}=\frac{\left(C_{t}-C_{t b}\right) \times N V}{1 \text { unit }}
$$


where $\mathrm{SER}_{\mathrm{u}}$ is the unit specific emission rate $(\mathrm{mg} / \mathrm{unit} / \mathrm{h}), C_{t}$ the concentration in exiting air $(t)\left(\mathrm{mg} / \mathrm{m}^{3}\right)$, $C_{t b}$ the concentration in entering air $\left(\mathrm{mg} / \mathrm{m}^{3}\right), N$ the air exchange rate $(1 / \mathrm{h}), Q$ the ventilation $\mathrm{rate}\left(\mathrm{m}^{3} / \mathrm{h}\right)$, and $V$ the volume of chamber $\left(\mathrm{m}^{3}\right)$.

There are many methods developed to assess the emission rates of building materials such as mathematical models with the consideration of some intricate factors [17-21]. Because of the diverse shapes of furniture product samples investigated in this study, it is not possible to directly assess the total surface areas of each sample product. Hence, as a simple method to assess the emission rates of such furniture products, equation (3.1) was used for all our target products, regardless surface area.

\subsection{The General Pattern of the VOC's Data}

A total of 39 target compounds were determined in this study, as tabulated in Table 2. Table 3 presents statistical summary of these 39 target VOCs to allow a direct comparison between five types of furniture products investigated in this study. The concentrations of target compounds varied greatly between the products. The results shown in Table 3 indicate that the highest equilibrium concentration $\left(\mu \mathrm{g} / \mathrm{m}^{3}\right)$ was recorded by toluene $(330 \pm 2.51)$, while the lowest was by bromodichloromethane $(0.28 \pm 0.19)$. If this comparison is made for all 5 products, the highest values were consistently seen by toluene (with an exception of ethylbenzene as the highest in the dining table). The equilibrium concentration levels of all individual VOCs (except the two dominant of toluene and ethylbenzene) are typically below $100 \mu \mathrm{g} / \mathrm{m}^{3}$.

In compliance with this finding, many authors have routinely found toluene as the predominant component of the VOCs released from furniture, based on both small- [18, 20, 22, 23] and large-scale chamber tests (environmental chamber) [24]. Note that a serious health concern has been raised with respect to toluene (e.g., birth defects) depending on its intake amount, exposure duration, genetic susceptibility, age, and so forth. For the reader's reference, the maximum concentration of toluene determined from three furniture types (i.e., desk chair, dining table, and sofa) in fact exceeded a strict guideline value of $80 \mathrm{ppb}\left(\sim 307 \mu \mathrm{g} / \mathrm{m}^{3}\right.$ in standard conditions $\left(25^{\circ} \mathrm{C}\right.$ and $1 \mathrm{~atm}$ pressure $)$ ) set as the minimum risk level of chronic duration [25]. If these data are evaluated in terms of the abundance of VOC types, dining table was recorded with the highest number (38 compounds). In contrast, the cabinet showed the least one ( 20 compounds), although it recorded the highest level of benzene $(2.45 \pm 1.28)$ among 5 types of furniture. Benzene is well known as a human carcinogen [26].

The emission rates of these types of furniture were also calculated to assess the relative intensity of their source strengths. As shown in Table 4, the emission rates of 39 target VOCs are summarized for each product. These emission rates are highly comparable to the pattern already described by concentration data $\left(\mu \mathrm{g} / \mathrm{m}^{3}\right)$. As can be expected, the highest emission rates were recorded from toluene for most products. The relative ordering of the TVOC emission rates, if compared between all five types of furniture, can be arranged in a highly consistent manner: dining table $>$ sofa $>$ desk chair $>$ bedside table $>$ cabinet (Figure 3).

The observed differences between individual furniture types reflect the differences in the properties of materials used for their production. To facilitate further evaluation of these emission data, all 39 compounds were evaluated in terms of 7 data groups by considering their chemical families: aromatic (AR), carbonyl (CBN), paraffin (PR), halogenated paraffin (HPR), halogenated olefin (HOL), terpenes (TER), and others (Table 2).

\subsection{Temporal Trend of VOC Emission Rates from Different Furniture Type}

In this paper, the emission rate of TVOC derived by the toluene response factor was evaluated along with the emission rates of all individual VOCs. TVOC is the one single parameter that is simpler and faster for the calculation of the concentrations (or emission rates) rather than evaluating several dozens of individual VOCs [27]. In the Republic of Korea, the Korean Ministry of Environment (KMOE) provides regulation 
TABLE 2: List of 39 target compounds investigated in this study.

\begin{tabular}{|c|c|c|c|c|c|}
\hline Order & Full name (short name) & Grouping* & CAS number & $\begin{array}{l}\text { Molecular weight } \\
\qquad\left(\mathrm{g} \mathrm{mol}^{-1}\right)\end{array}$ & Chemical formula \\
\hline 1 & Benzene (B) & $\mathrm{AR}$ & $71-43-2$ & 78.1 & $\mathrm{C}_{6} \mathrm{H}_{6}$ \\
\hline 2 & Toluene $(\mathrm{T})$ & $\mathrm{AR}$ & $108-88-3$ & 82.1 & $\mathrm{C}_{6} \mathrm{H}_{5} \mathrm{CH}_{3}$ \\
\hline 3 & Ethylbenzene (E) & AR & $100-41-4$ & 106.2 & $\mathrm{C}_{6} \mathrm{H}_{5} \mathrm{C}_{2} \mathrm{H}_{5}$ \\
\hline 4 & m,p-Xylene (m,p-X) & $\mathrm{AR}$ & $\begin{array}{l}108-38-3 \\
106-42-3\end{array}$ & 106.2 & $\mathrm{C}_{6} \mathrm{H}_{4}\left(\mathrm{CH}_{3}\right)_{2}$ \\
\hline 5 & Styrene (S) & $\mathrm{AR}$ & $100-42-5$ & 104.2 & $\mathrm{C}_{6} \mathrm{H}_{5} \mathrm{C}_{2} \mathrm{H}_{3}$ \\
\hline 6 & o-Xylene (o-X) & AR & $95-47-6$ & 106.2 & $\mathrm{C}_{6} \mathrm{H}_{4}\left(\mathrm{CH}_{3}\right)_{2}$ \\
\hline 7 & 3-Ethyltoluene (3-ET) & $\mathrm{AR}$ & $620-14-04$ & 120.2 & $\mathrm{C}_{6} \mathrm{H}_{5} \mathrm{CH}_{3} \mathrm{C}_{2} \mathrm{H}_{5}$ \\
\hline 8 & 4-Ethyltoluene (4-ET) & $\mathrm{AR}$ & $622-96-8$ & 120.2 & $\mathrm{C}_{6} \mathrm{H}_{5} \mathrm{CH}_{3} \mathrm{C}_{2} \mathrm{H}_{6}$ \\
\hline 9 & 1,3,5-Trimethylbenzene (TMB-1) & $\mathrm{AR}$ & $108-67-8$ & 120.2 & $\mathrm{C}_{6} \mathrm{H}_{3}\left(\mathrm{CH}_{3}\right)_{3}$ \\
\hline 10 & 2-Ethyltoluene (2-ET) & $\mathrm{AR}$ & $611-14-3$ & 120.2 & $\mathrm{C}_{6} \mathrm{H}_{5} \mathrm{CH}_{3} \mathrm{C}_{2} \mathrm{H}_{5}$ \\
\hline 11 & 1,2,4-Trimethylbenzene (TMB-2) & $\mathrm{AR}$ & $95-63-6$ & 120.2 & $\mathrm{C}_{6} \mathrm{H}_{3}\left(\mathrm{CH}_{3}\right)_{3}$ \\
\hline 12 & 1,4-Dichlorobenzene (DCB) & $\mathrm{AR}$ & $106-46-7$ & 147.0 & $\mathrm{C}_{6} \mathrm{H}_{4} \mathrm{Cl}_{2}$ \\
\hline 13 & 1,2,4,5-Tetramethylbenzene (TMB-3) & $\mathrm{AR}$ & $95-93-2$ & 134.2 & $\mathrm{C}_{6} \mathrm{H}_{2}\left(\mathrm{CH}_{3}\right)_{4}$ \\
\hline 14 & 4-Methyl-2-pentanone (MP) & $\mathrm{CBN}$ & $108-10-1$ & 100.2 & $\mathrm{C}_{6} \mathrm{H}_{12} \mathrm{O}$ \\
\hline 15 & n-Butyl acetate (BA) & $\mathrm{CBN}$ & $123-86-4$ & 116.2 & $\mathrm{C}_{6} \mathrm{H}_{12} \mathrm{O}_{2}$ \\
\hline 16 & Nonanal (NL) & $\mathrm{CBN}$ & $124-19-6$ & 142.2 & $\mathrm{C}_{8} \mathrm{H}_{17} \mathrm{CHO}$ \\
\hline 17 & Decanal (DL) & $\mathrm{CBN}$ & $112-31-2$ & 156.3 & $\mathrm{C}_{9} \mathrm{H}_{19} \mathrm{CHO}$ \\
\hline 18 & Hexane (HX) & PR & $110-54-3$ & 86.2 & $\mathrm{C}_{6} \mathrm{H}_{14}$ \\
\hline 19 & Heptane (HP) & PR & $142-82-5$ & 100.2 & $\mathrm{C}_{7} \mathrm{H}_{16}$ \\
\hline 20 & Octane (O) & PR & $111-65-9$ & 114.2 & $\mathrm{C}_{8} \mathrm{H}_{18}$ \\
\hline 21 & Nonane (NN) & PR & $111-84-2$ & 128.3 & $\mathrm{C}_{9} \mathrm{H}_{20}$ \\
\hline 22 & Decane (DE) & PR & $124-18-5$ & 142.3 & $\mathrm{C}_{10} \mathrm{H}_{22}$ \\
\hline 23 & Undecane (U) & PR & $1120-21-4$ & 156.3 & $\mathrm{C}_{11} \mathrm{H}_{24}$ \\
\hline 24 & Dodecane (D) & PR & $112-40-3$ & 170.3 & $\mathrm{C}_{12} \mathrm{H}_{26}$ \\
\hline 25 & Tridecane (TI) & $\mathrm{PR}$ & $629-50-5$ & 184.4 & $\mathrm{C}_{13} \mathrm{H}_{28}$ \\
\hline 26 & Tetradecane (TE) & PR & $629-59-4$ & 198.4 & $\mathrm{C}_{14} \mathrm{H}_{30}$ \\
\hline 27 & Pentadecane $(\mathrm{P})$ & PR & $629-62-9$ & 212.4 & $\mathrm{C}_{15} \mathrm{H}_{32}$ \\
\hline 28 & Hexadecane (HD) & $\mathrm{PR}$ & $629-73-2$ & 224.4 & $\mathrm{C}_{16} \mathrm{H}_{34}$ \\
\hline 29 & 1,2-Dichloroethane (DCE) & HPR & $107-06-2$ & 99.0 & $\mathrm{C}_{2} \mathrm{H}_{4} \mathrm{Cl}_{2}$ \\
\hline 30 & 1,1,1-Trichloroethane (TCE-1) & HPR & $71-55-6$ & 133.4 & $\mathrm{C}_{2} \mathrm{H}_{3} \mathrm{Cl}_{3}$ \\
\hline 31 & 1,2-Dichloropropane (DCP) & HPR & $78-87-5$ & 113.0 & $\mathrm{C}_{3} \mathrm{H}_{6} \mathrm{Cl}_{2}$ \\
\hline 32 & Bromodichloromethane (BCM) & HPR & $75-27-4$ & 163.8 & $\mathrm{CHBrCl}_{2}$ \\
\hline 33 & Trichloroethylene (TCE-2) & $\mathrm{HOL}$ & $79-01-6$ & 131.4 & $\mathrm{C}_{2} \mathrm{HCl}_{3}$ \\
\hline 34 & Tetrachloroethylene (TCE-3) & HOL & $127-18-4$ & 165.8 & $\mathrm{C}_{2} \mathrm{Cl}_{4}$ \\
\hline 35 & $\alpha$-Pinene $(\alpha-\mathrm{P})$ & TER & $2437-95-8$ & 136.2 & $\mathrm{C}_{10} \mathrm{H}_{16}$ \\
\hline 36 & $\beta$-Pinene $(\beta$-P) & TER & $18172-67-3$ & 136.2 & $\mathrm{C}_{10} \mathrm{H}_{16}$ \\
\hline
\end{tabular}


TABLE 2: Continued.

\begin{tabular}{lccccc}
\hline Order & Full name (short name) & Grouping* & CAS number & $\begin{array}{c}\text { Molecular weight } \\
\left(\mathrm{g} \mathrm{mol}^{-1}\right)\end{array}$ & Chemical formula \\
\hline 37 & Limonene (LMN) & TER & $138-86-3$ & 136.2 & $\mathrm{C}_{10} \mathrm{H}_{16}$ \\
38 & Ethyl acetate and chloroform (EC) & other & $141-78-6$ & 88.1 & $\mathrm{CH}_{3} \mathrm{COOC}_{2} \mathrm{H}_{5}$ \\
& & & $67-66-3$ & 119.4 & $\mathrm{CHCl}_{3}$ \\
39 & 1-Butanol (BL) & other & $71-36-3$ & 74.1 & $\mathrm{C}_{4} \mathrm{H}_{9} \mathrm{OH}$ \\
\hline
\end{tabular}

*Acronyms for VOC groups: AR: aromatic, CBN: carbonyl, PR: paraffin, HPR: halogenated paraffin, HOL: halogenated olefin, ER: terpenes, and others.

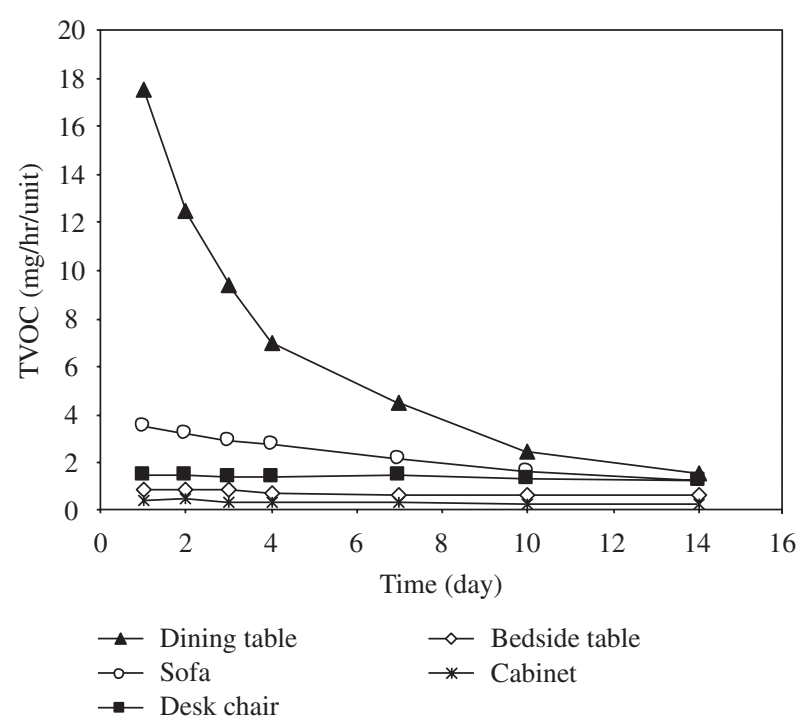

FIGURE 3: Emission rate of TVOC for 5 furniture types as a function of elapsed time.

guidelines for VOC emissions from building materials such as in terms of TVOC [28, 29]. The results of our study derived for each product are thus compared in terms of TVOC, as shown in Figure 3. The TVOC data collected within 14 days (after sample production) show greatly distinguishable patterns between the products. The highest equilibrium emission rate of TVOC (mg/hr/unit) was derived from dining table (7.85), while the lowest one was from cabinet (0.39). The emission rates of all 5 furniture types tended to gradually decrease toward the end of the tests (up to 14 days), as they approached equilibrium. Higher emission rates were generally produced within a few hours, and then the values decreased systematically. As seen in Figure 3, the total individual emission rates of dining table, sofa, and desk chair became similar after 14 days. The other two also approached the least values but at much reduced rates.

As mentioned, the concentration data for all 39 target VOCs were further evaluated after being grouped: AR, CBN, PR, HPR, HOL, TER, and others. As shown in Table 5, statistical summary of their emission rates is tabulated for each type of studied furniture. Among all chemical groups, AR is the most dominant. In contrast, HPR and HOL were generally negligible, as they were undetectable in many cases (bedside table, sofa, and cabinet). If the relative ordering of emission rates is assessed, these chemical groups can be arranged in the following order: AR $>$ TER $>$ CBN $>$ others $>$ PR $>$ HOL $>$ HPR. Moreover, if we assess the relative contribution of individual groups to the total emission rate of each furniture type, the percentage of AR emitted from the furniture is predominant for all the products with moderate variations (Figure 4). Sofa was seen to emit the least proportion of aromatic VOCs (38.2\%), while desk chair gave most aromatic VOCs out $(94.6 \%)$. 


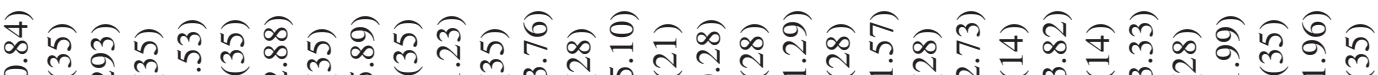
e m d c n d d d

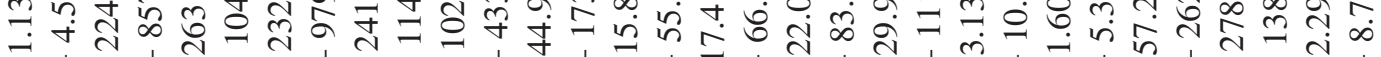
H I H I I H l H I H I H I H I 느의

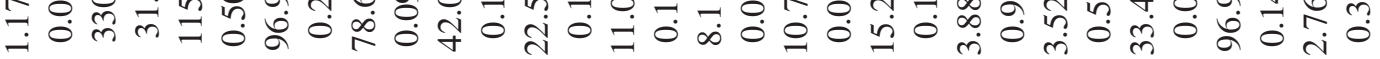

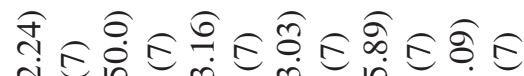

d

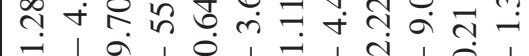

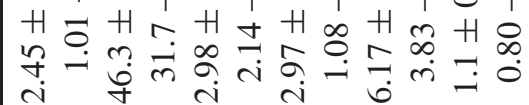

สิ ।

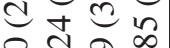

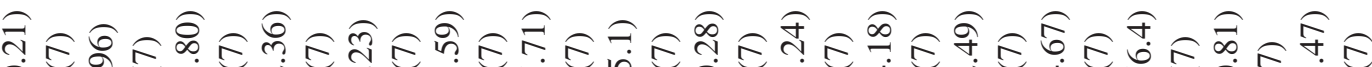

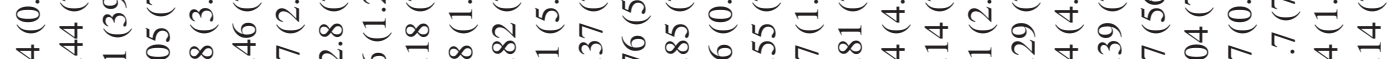

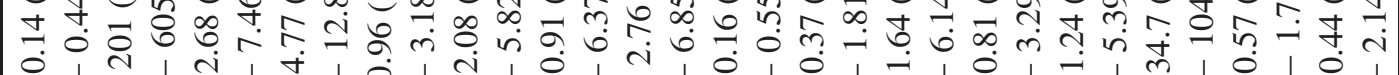

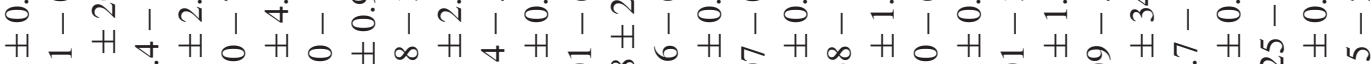

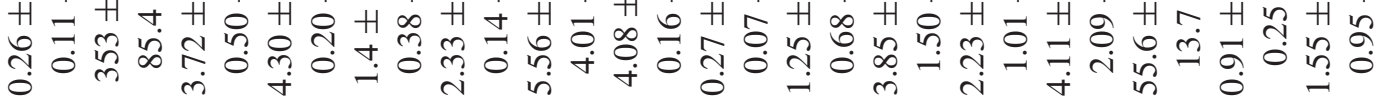

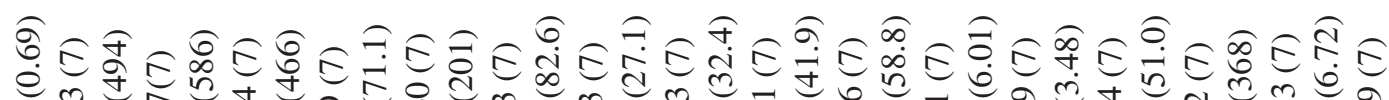
m

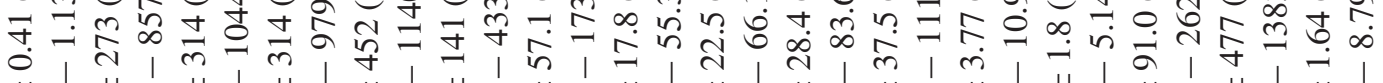

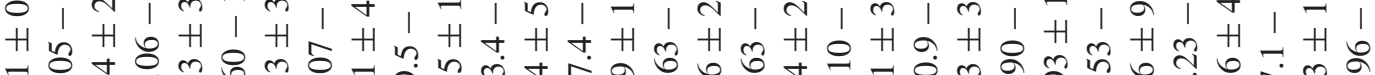
웅 岁。

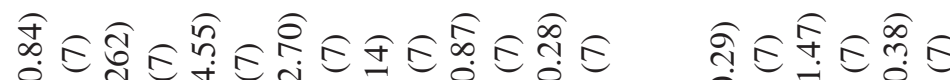

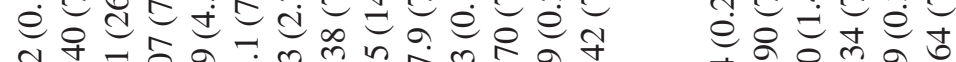

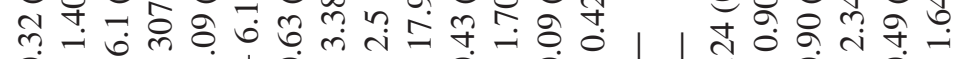

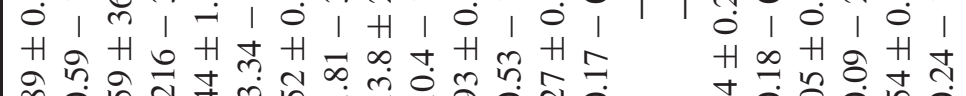

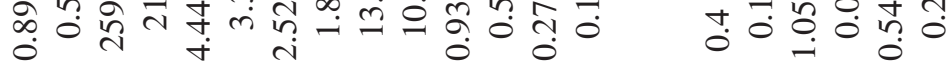

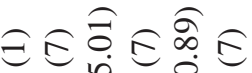

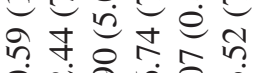

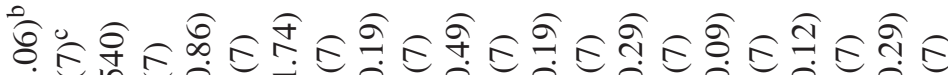

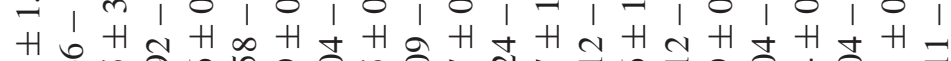
तु กิ

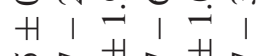

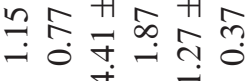

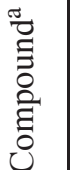

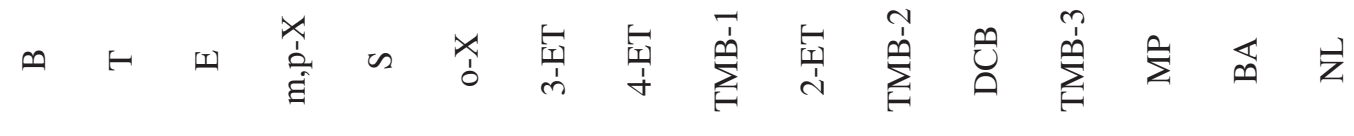
这 $-$ 


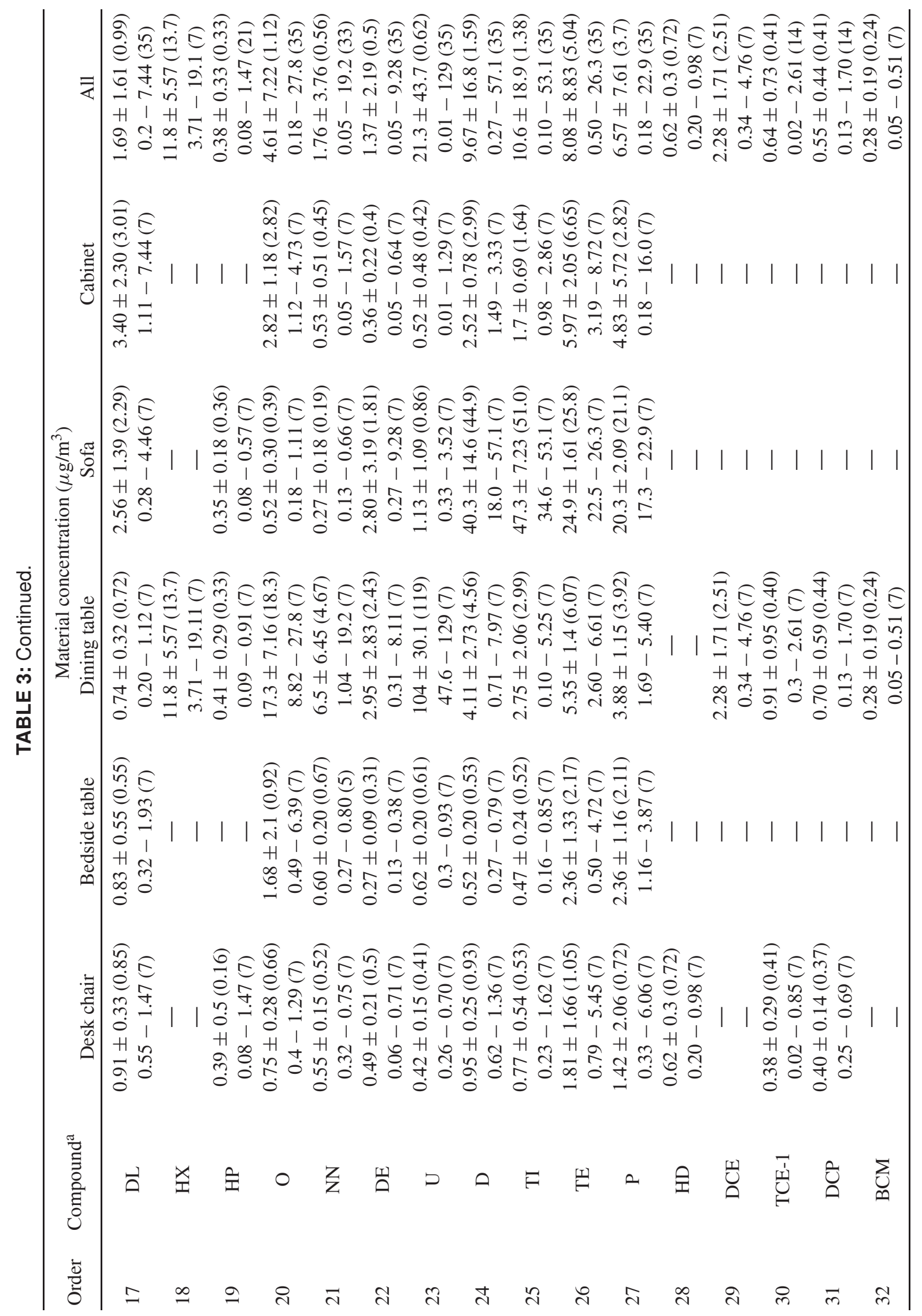




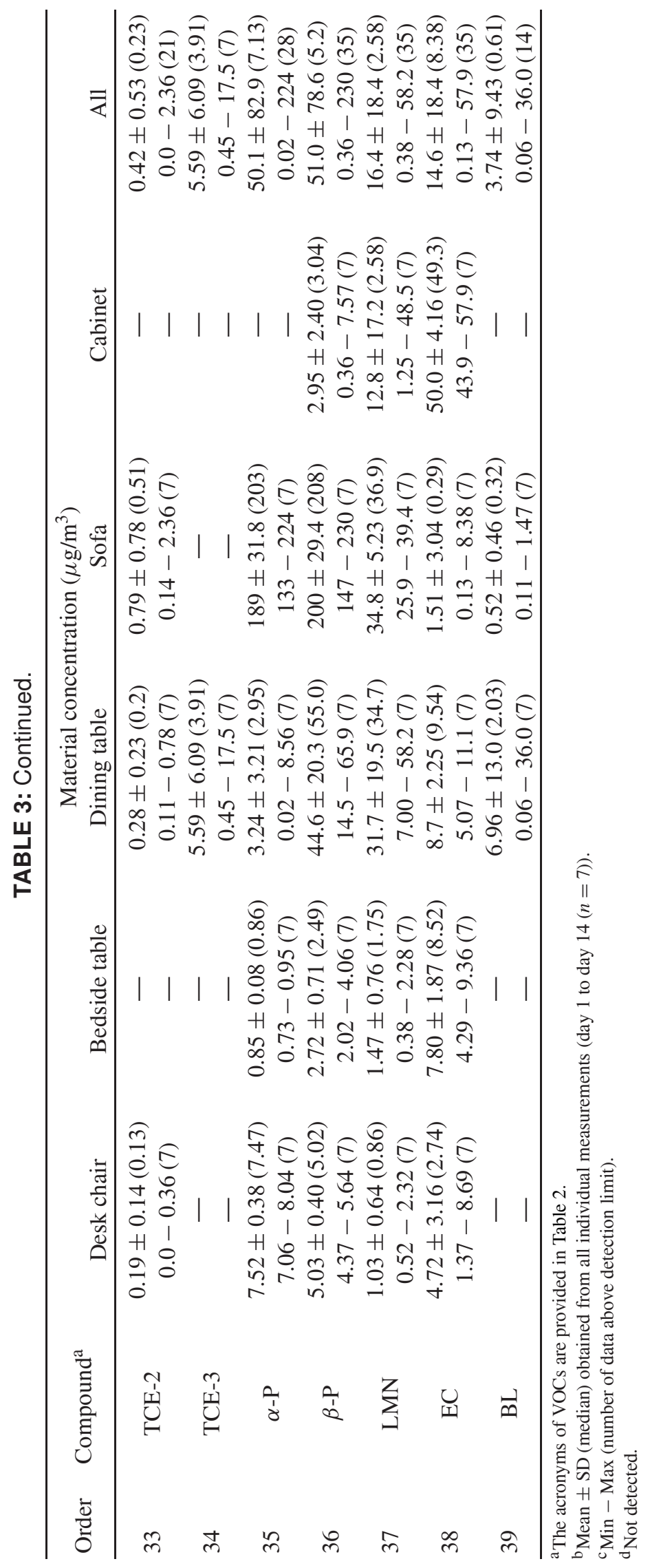




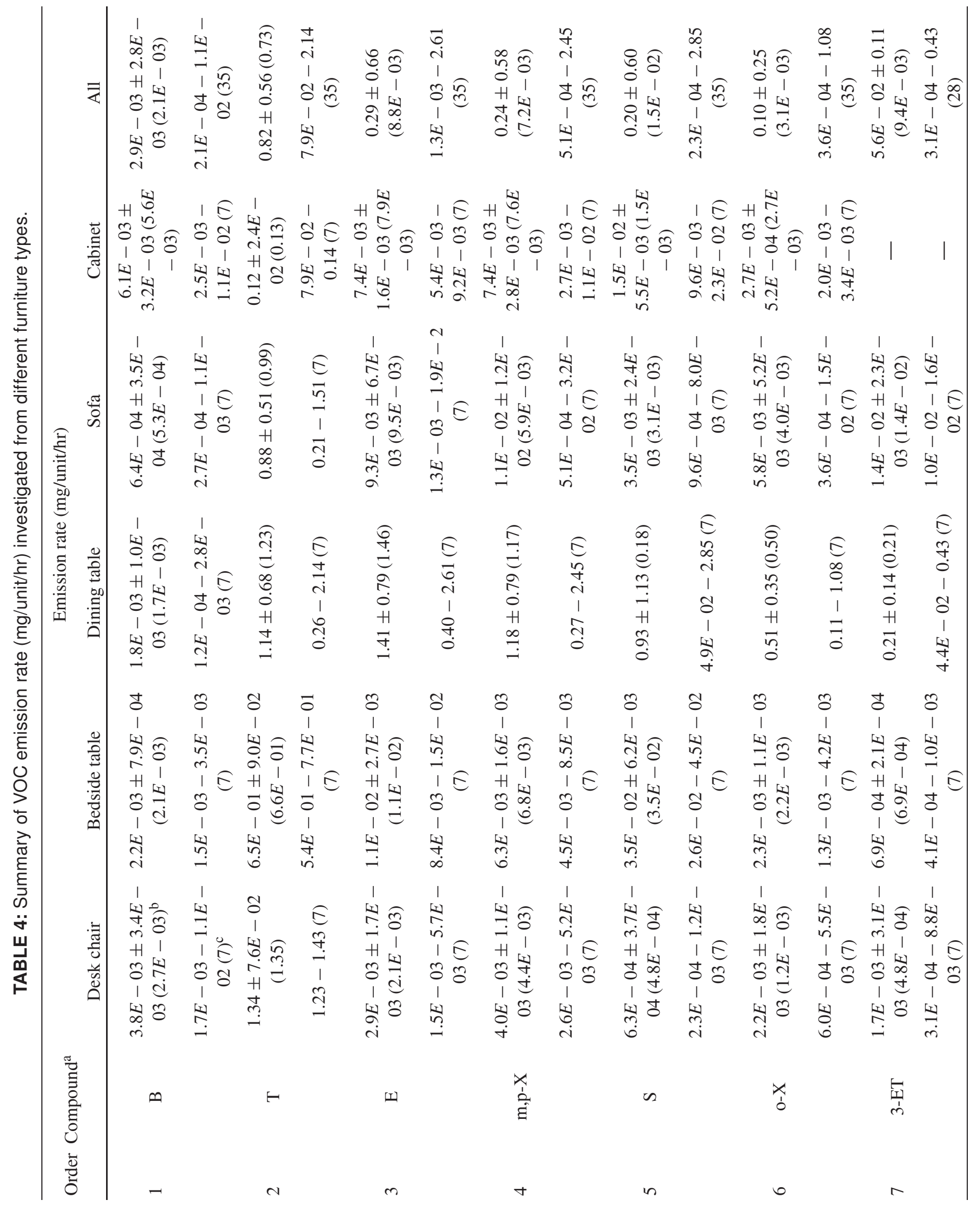




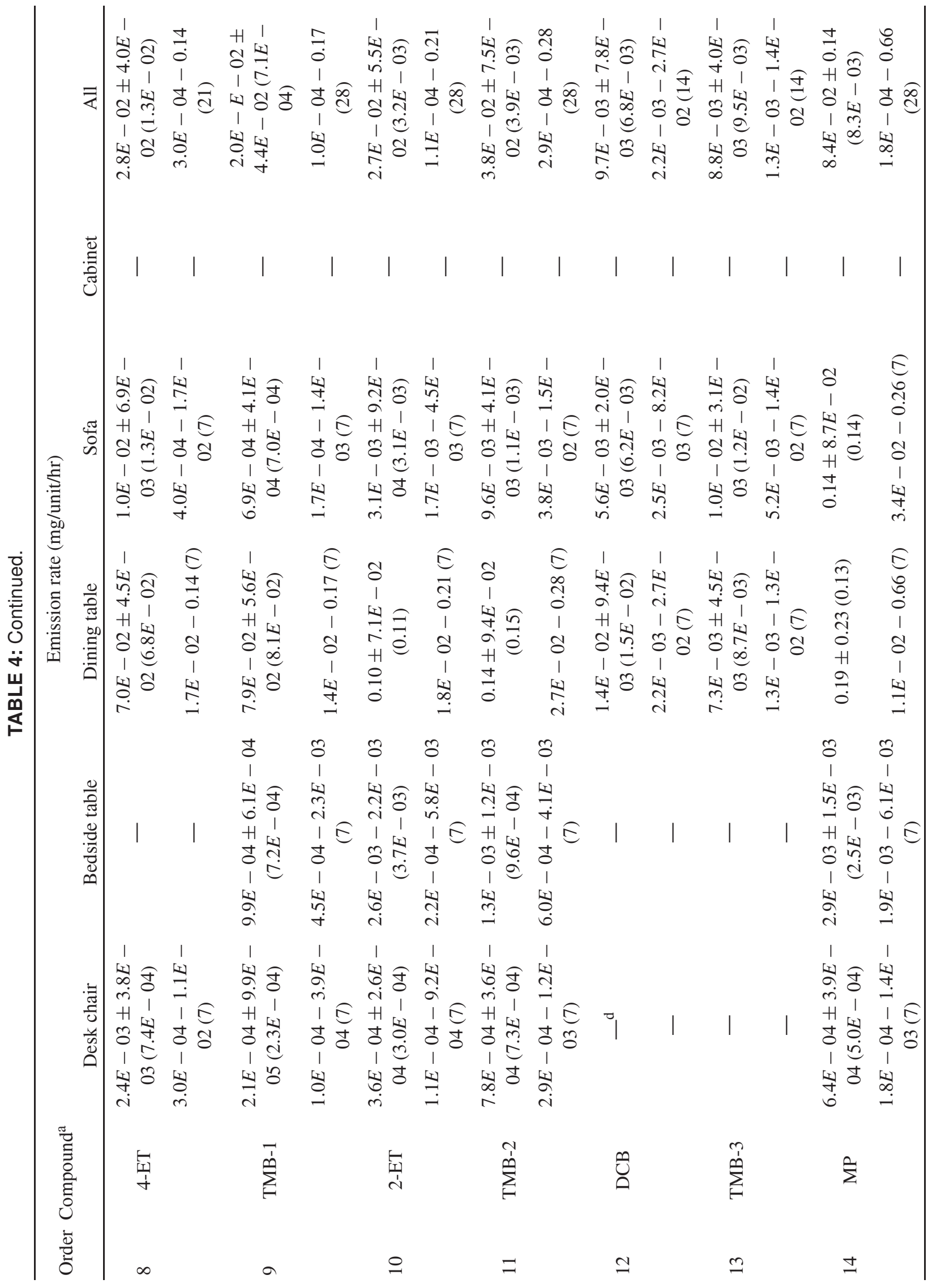




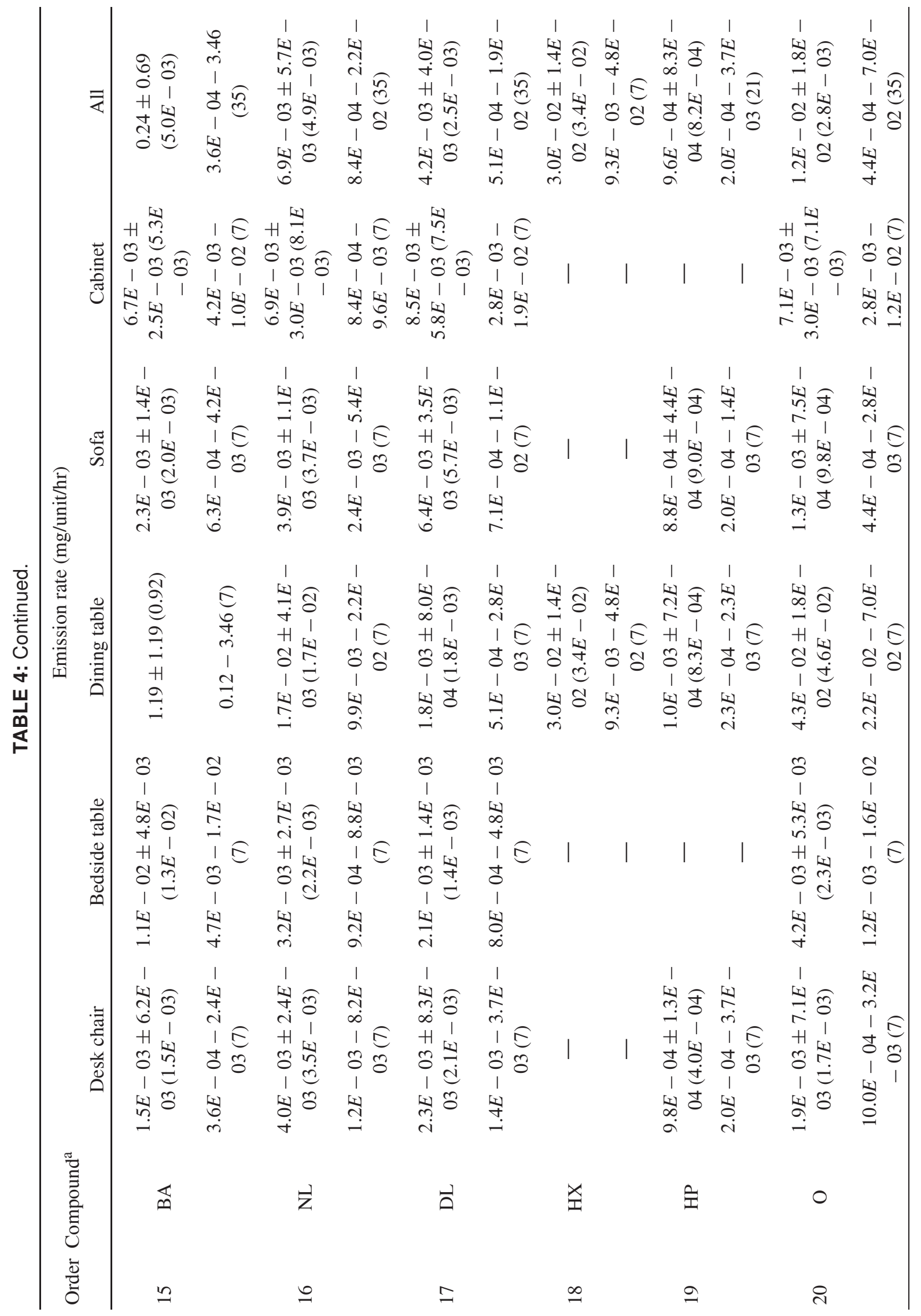




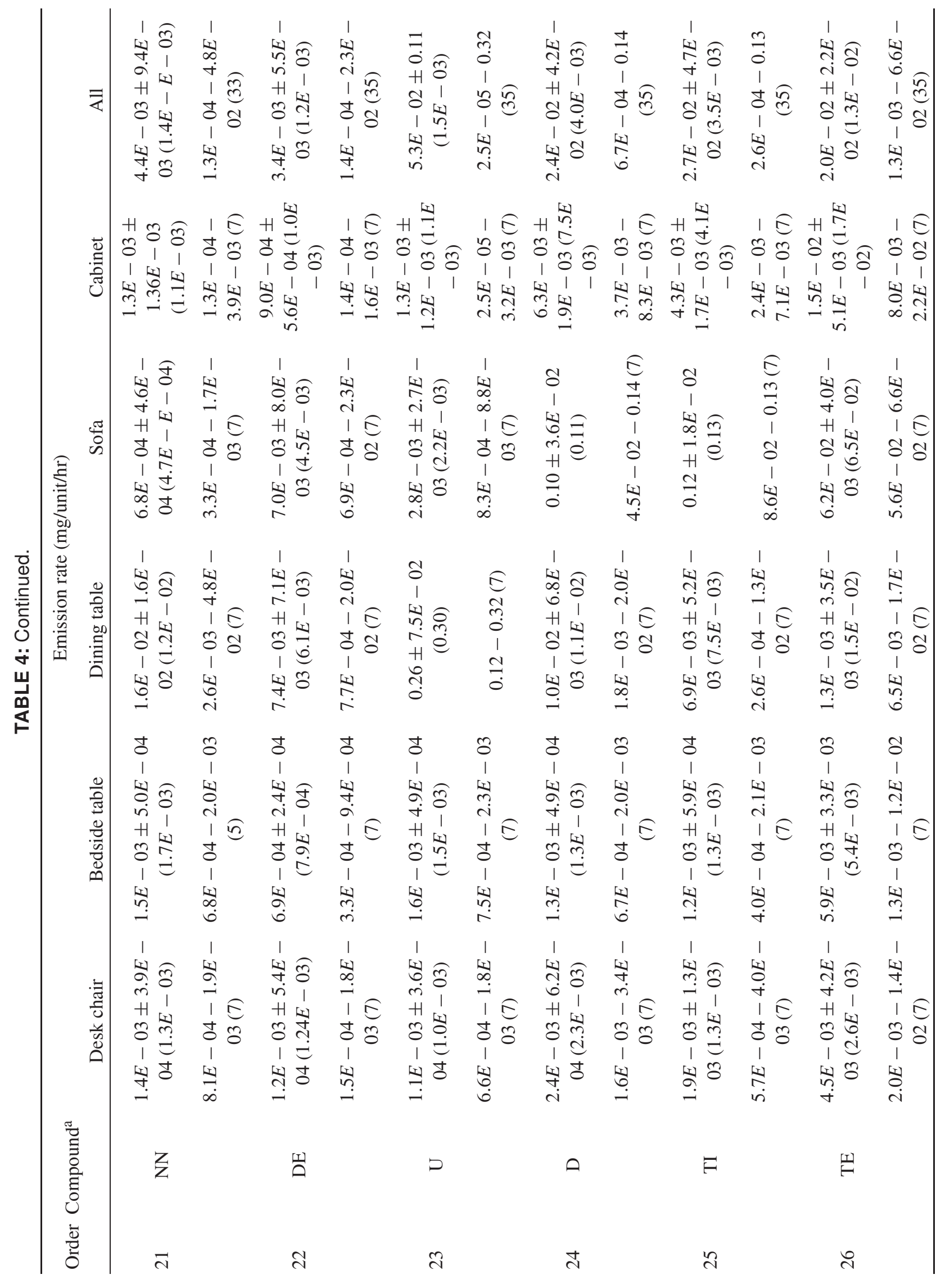




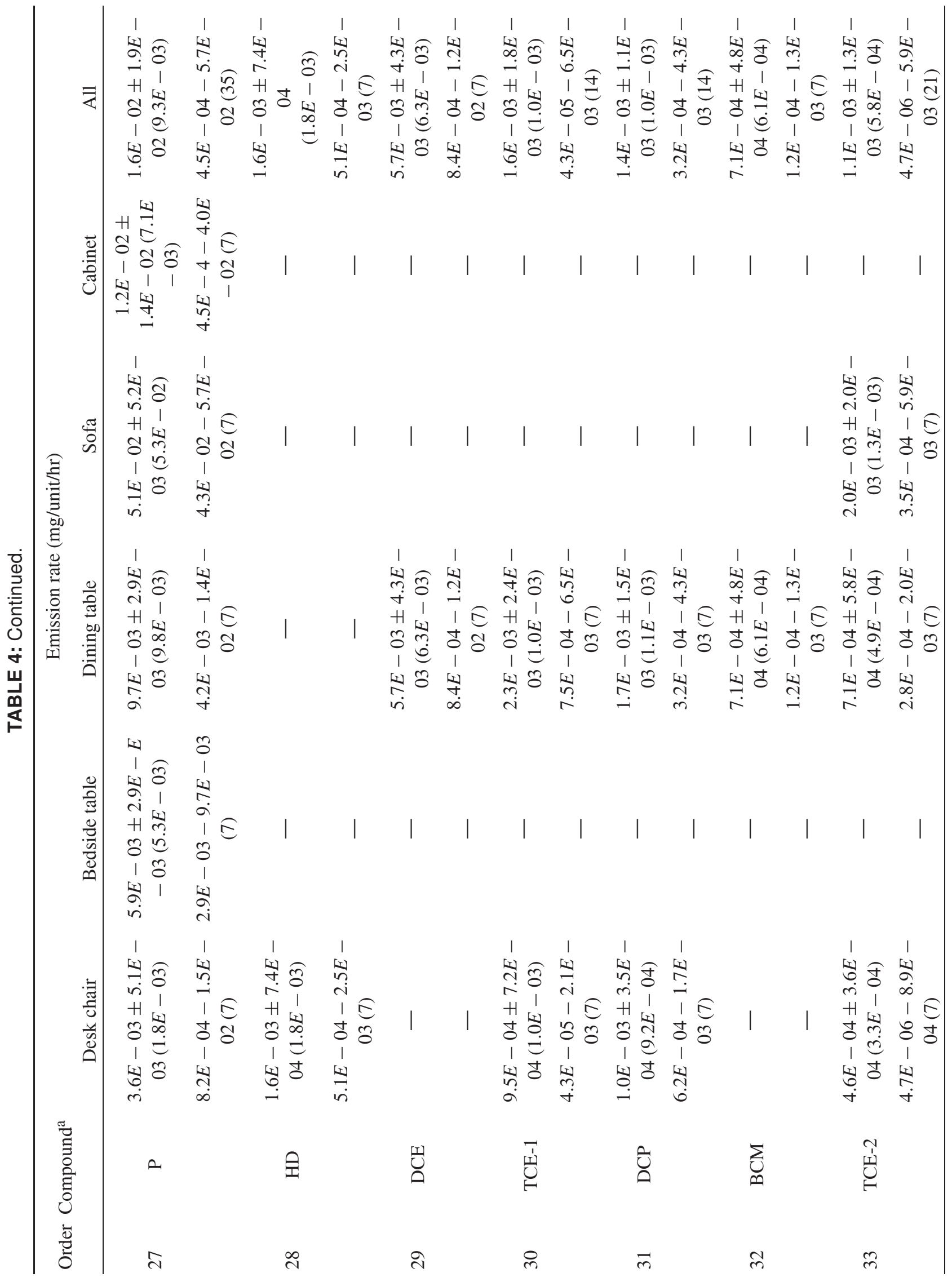




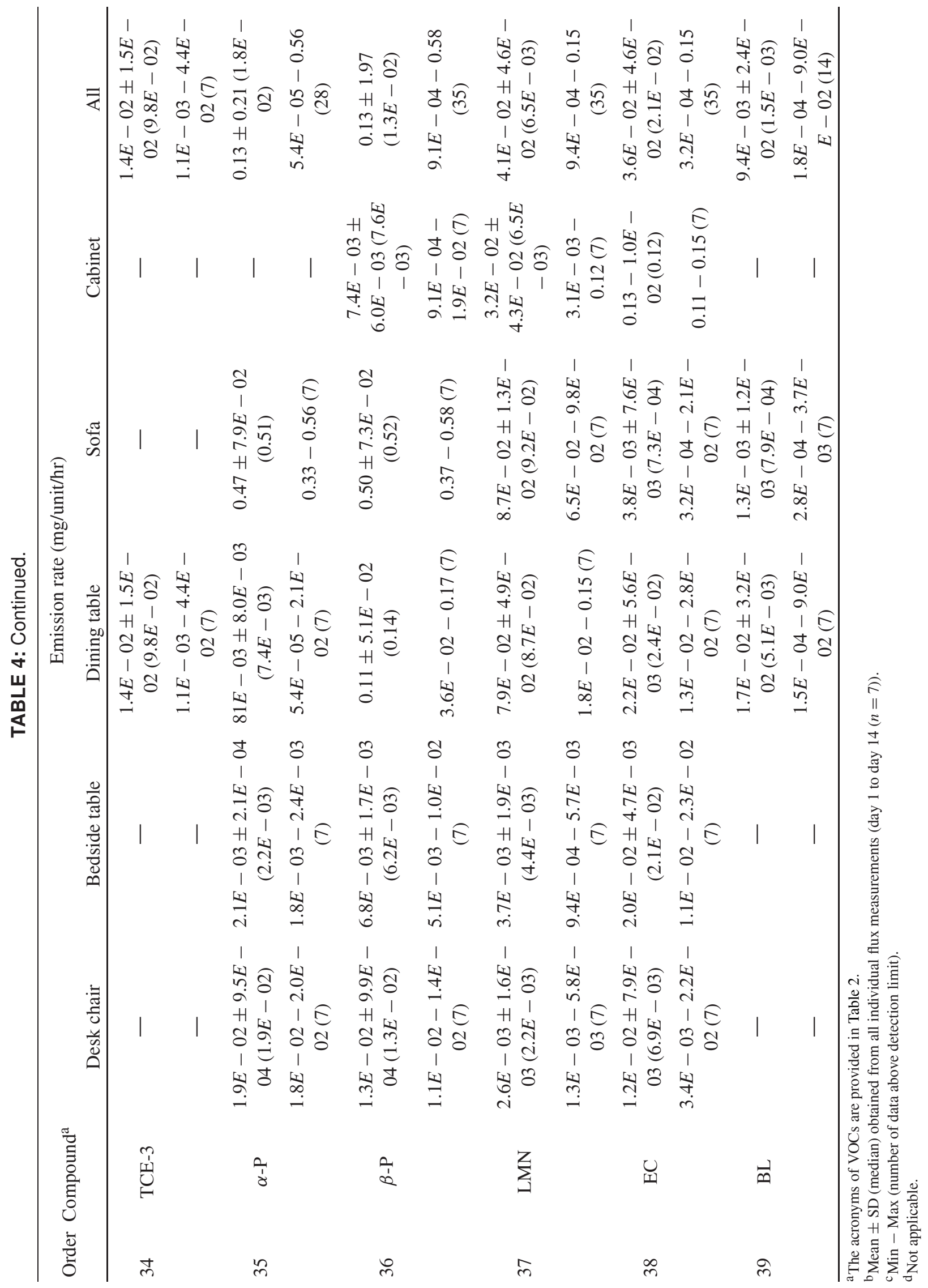




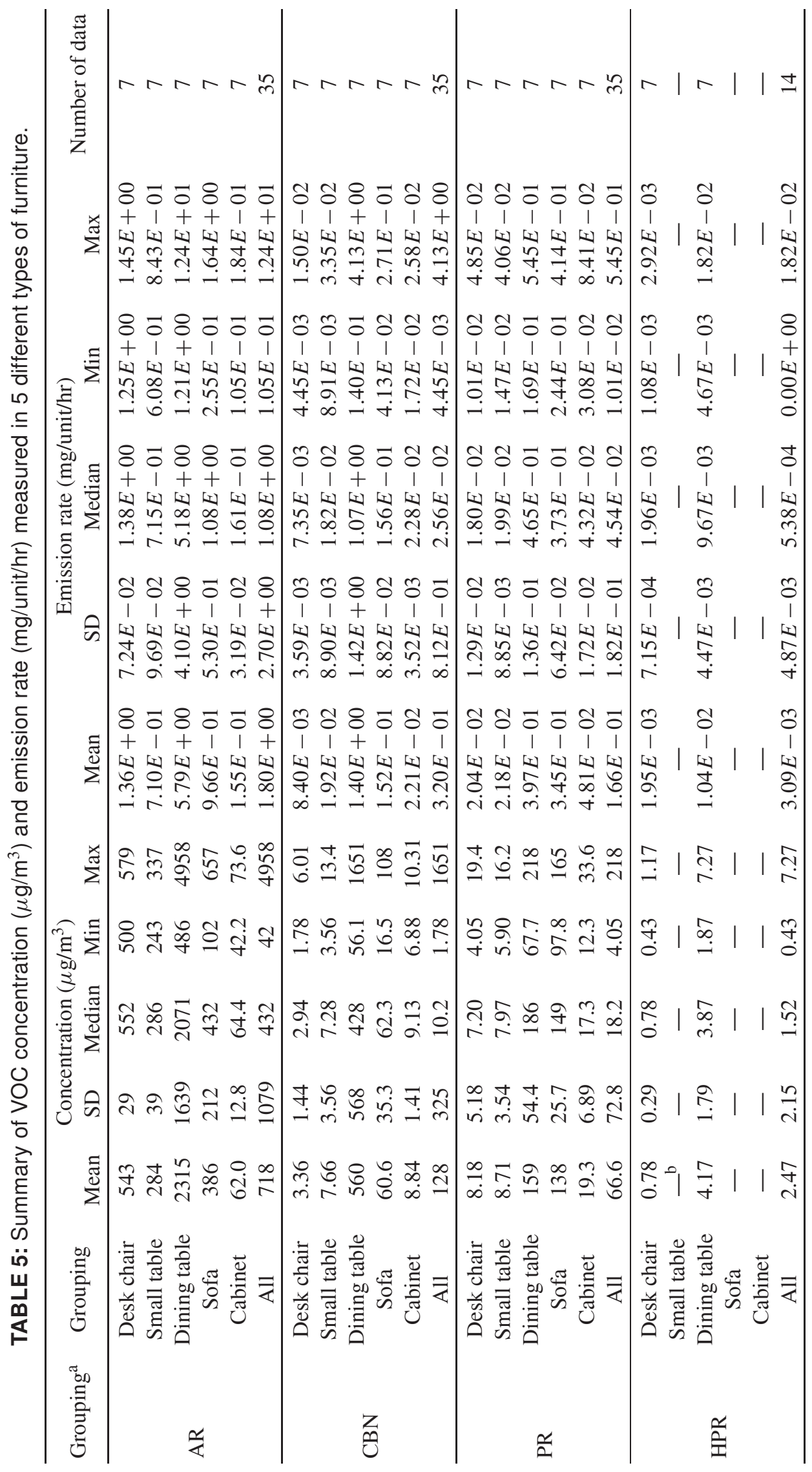




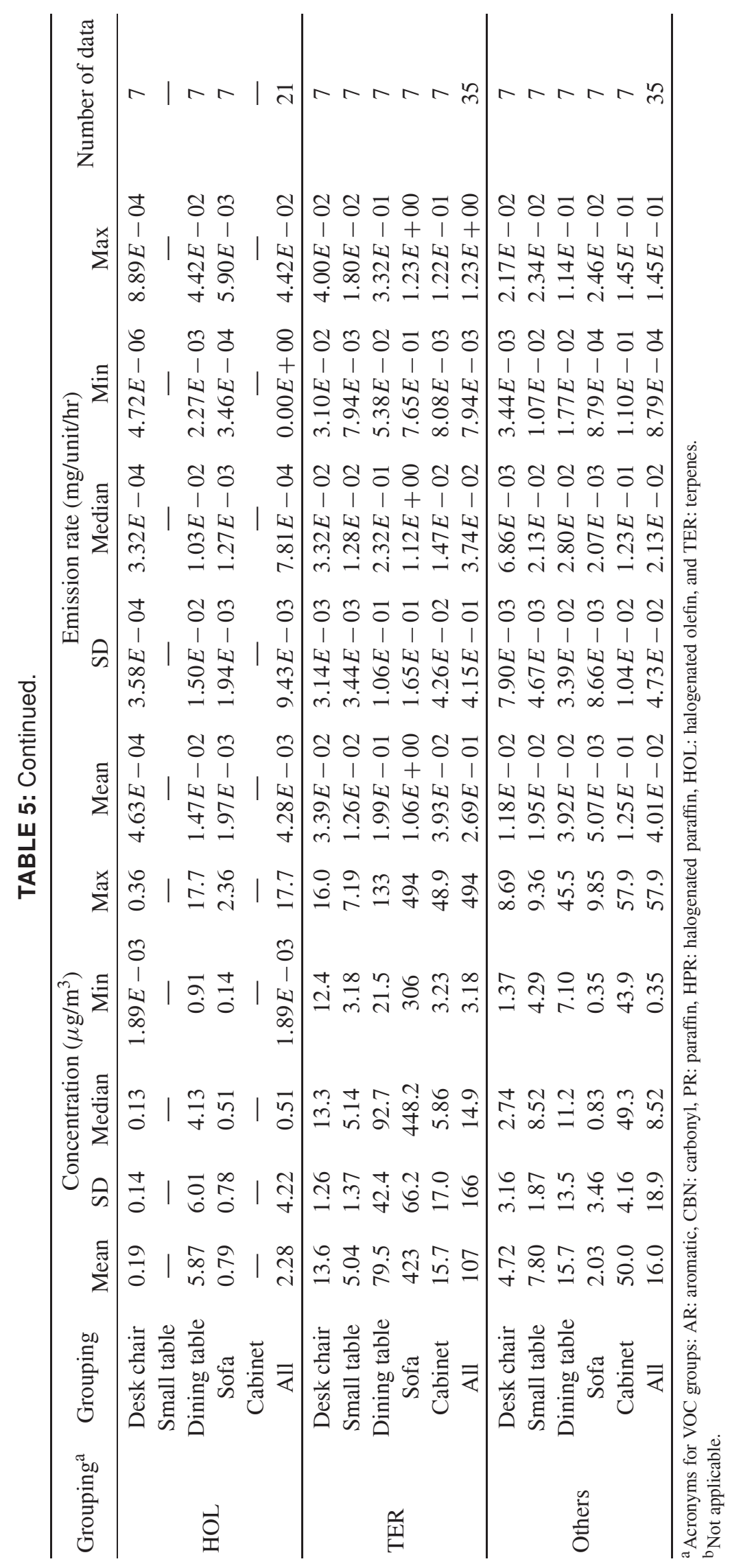




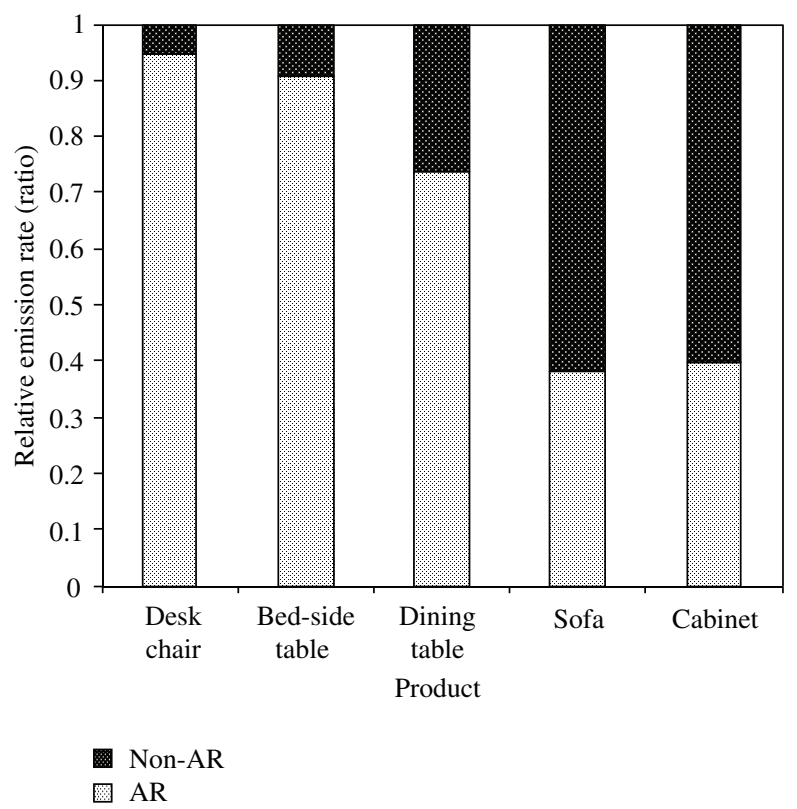

FIGURE 4: Relative emission rate ratio of VOCs released from each furniture types: Aromatic (AR) versus non-aromatic (non-AR).

To learn more about the relative role of the AR group from all our target furniture products examined in this study, the emission rates of individual components in the AR are compared to each other between different furniture types. In light of absolute dominance of aromatics, the emission patterns of VOCs can be examined between individual aromatics and all the remaining components (Figure 5). The predominance of toluene is seen from 4 products (desk chair, bedside table, sofa, and cabinet). In contrast, the pattern for dining table is fairly comparable between different components. This unique pattern of relative compositional changes between different furniture products suggests that the different emission signatures of furniture products can be maintained through time in a relative maintenance sense.

\subsection{Factors Affecting Emission Rates from Furniture}

The selected furniture for this study consists of the primary components of MDF, HDF, PP, and several coating materials (e.g., PU leather, PVC, and LPM). The use of MDF, HDF, and PB is found in a wide range of household tools and building decoration materials. Wood-based panels, wood-based composites, laminated office furniture, laminate flooring, and engineer flooring are the common form of furniture products made by MDF, HDF, and PB (e.g., [19, 22, 30, 31]). The results showed that a large number of VOCs can be emitted from the furniture made of such materials. Reference [32] reported that unfinished PB and MDF made from North America emitted several types of VOCs, although HDF did not contribute to indoor VOCs emission.

In this study, we intended to investigate the emission rates of VOCs from diverse furniture products. Among the VOCs detected, toluene and $\alpha$-pinene from a sofa sample recorded the largest mean equilibrium concentrations (353 and $189 \mu \mathrm{g} / \mathrm{m}^{3}$, resp.). Reference [33] used the toluene and $\alpha$-pinene to evaluate VOC emission rates from a number of potential sources, including wool carpet, nylon carpet, and cotton curtain. These authors conducted two types of experiments to induce both adsorption (in which toluene and $\alpha$-pinene were introduced into the chamber) and desorption (in which only clean air was brought in). The results of this study indicated that the adsorption of $\alpha$-pinene was higher than that of toluene for all testing materials, while the desorption of these 2 chemicals was not greatly influenced by the materials. In addition to toluene and $\alpha$-pinene, other major VOCs found indoor (e.g., from solvent-based alkyd paint used indoor) commonly 


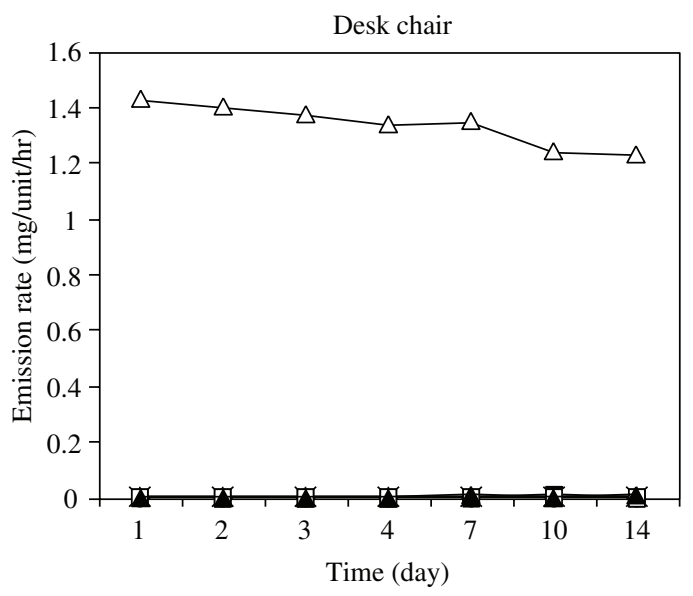

(a)

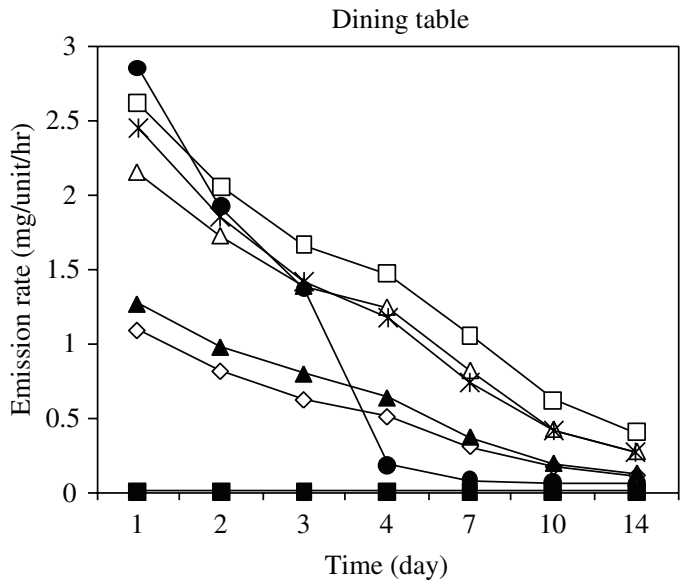

(c)

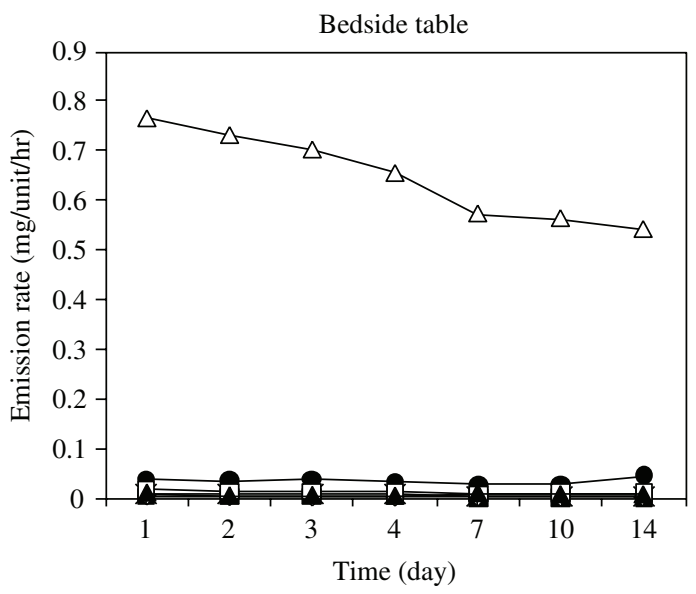

(b)

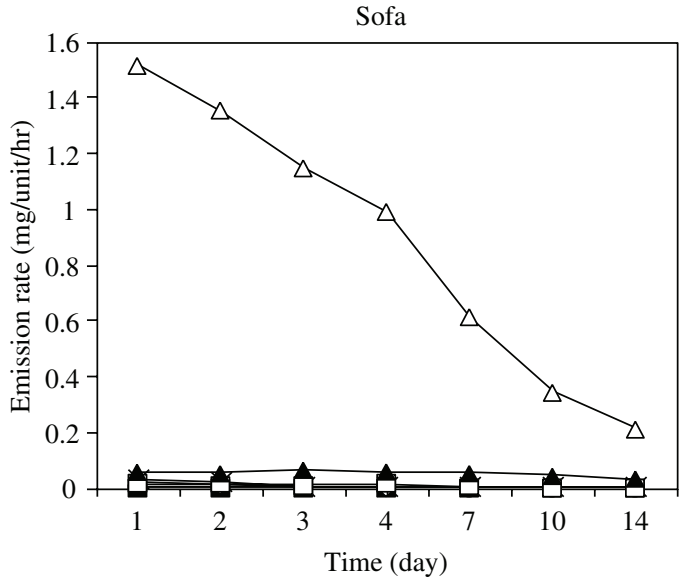

(d)

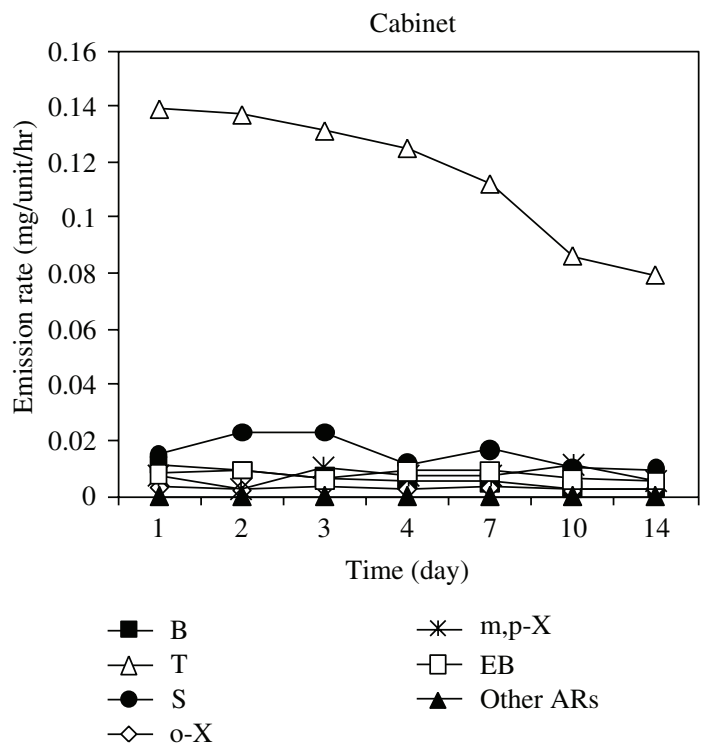

(e)

FIGURE 5: Temporal emission trends of aromatic components including benzene, toluene, ethylbenzene, xylene, styrene, and all other minor aromatics. 
include carbonyl compounds (i.e., acetone, hexanal, pentanal, heptanal, nonanal, octanol, decanal, etc.) [20]. The primary VOC components (i.e., formaldehyde, benzene, toluene, ethylbenzene, styrene, and xylene) emitted from PP flooring, wallpaper assemblies, and plywood assemblies (residential house units) were, however, reduced considerably after a bake-out procedure [23]. In our experiment, as the ending period (14 days) approached, the target furniture products generally showed a several-fold reduction in emission magnitude (Figure 5). VOC levels from our PB furniture products were not high with equilibrium emission rates of 0.78 (bedside table) and $0.39 \mathrm{mg} / \mathrm{unit} / \mathrm{h}$ (cabinet). In contrast, [22] found that the PB specimens emitted greater amounts of VOC that are comparable to engineered flooring. In addition, dining table and sofa made of foam and PU were found to exhibit greatly enhanced VOC levels relative to the others.

Typically, the surface of furniture is coated with some feasible coating agents for aesthetic purposes as well as to prevent damage. Initially, it was expected that the VOC levels released from coated furniture (bed-site table and cabinet's surfaces: LPM, PVC, and PP) should be different from those uncoated ones (e.g., surface of table chair, dining table, and sofa made of foam and PU leather). However, the results of our study indicated that there were no significant differences in the emission strengths of uncoated and coated furniture in terms of magnitude. In compliance with our findings, TVOC emission rates of nonveneered MDF and PB (such as low-pressure melamine, decorative lm, and UV curable vanish) were not much different from the patterns of coated products [22]. In addition, VOC emission rates of woodbased panels generally exhibited gradually decreasing trends through time, although their highest values were most commonly seen a day after installation [30]. This pattern is thus highly comparable to that seen in this study.

\subsection{Comparison of VOC Emission Rates between Different Studies}

To learn more about the emission patterns of VOCs from diverse furniture and materials used in households or buildings, the results of TVOC and individual aromatics measured from previous studies are compiled in Table 6. Although these emission data are often expressed in different units $\left(\mu \mathrm{g} \mathrm{m}^{-3}\right.$ and $\left.\mu \mathrm{g} \mathrm{m}^{-2} \mathrm{~h}^{-1}\right)$, these values are used directly to assess their emission patterns in association with diverse experimental setups used for each study. The results show that there are moderate differences among different types of components determined via the chamber study. Most importantly, toluene is commonly recorded as the predominant component in furniture used in both public facilities and in private housing units $([23,35]$, this study). However, the measurements made in home and office environments did not provide a quantitative basis for the quantification of toluene [34]. Depending on coating conditions of the furniture type (polishing, varnishing, or noncoating), the concentration levels of these components can widely vary by such factors as agitation [39, 40] and temperature [23]. The emission data were further compared by the magnitude $\left(\mu \mathrm{g} \mathrm{m}^{-2} \mathrm{~h}^{-1}\right.$ ) of a number of wood-based products. However, the patterns were seen to deviate greatly among furniture types $[30,36,38]$. Note that emissions of hardwood and softwood are not coincident with the patterns seen in other studies. Instead, their emissions were dominated by acid acetic and terpenes [37]. As such, the emission characteristics of VOCs from different furniture types are suggested to be affected mainly by the type of materials used for their construction and the way those sampling units are deployed.

\section{CONCLUSIONS}

In this paper, the emission rates of VOC from common furniture used in households and buildings were measured by using 5 furniture samples (desk chair, bedside table, dining table, sofa, and cabinet) through time (up to 14 days) after two weeks of their production. The results showed that toluene and $\alpha$-pinene were the most dominant components of emission, and most VOCs exhibited similarly decreasing trends through time. The relative ordering of emission rates for all five furniture types, if assessed in terms of TVOCs, was highly consistent through time: dining table $>$ sofa $>$ desk chair $>$ bedside table $>$ cabinet. This comparison is extended further to different chemical groups; their relative ordering can be arranged in 


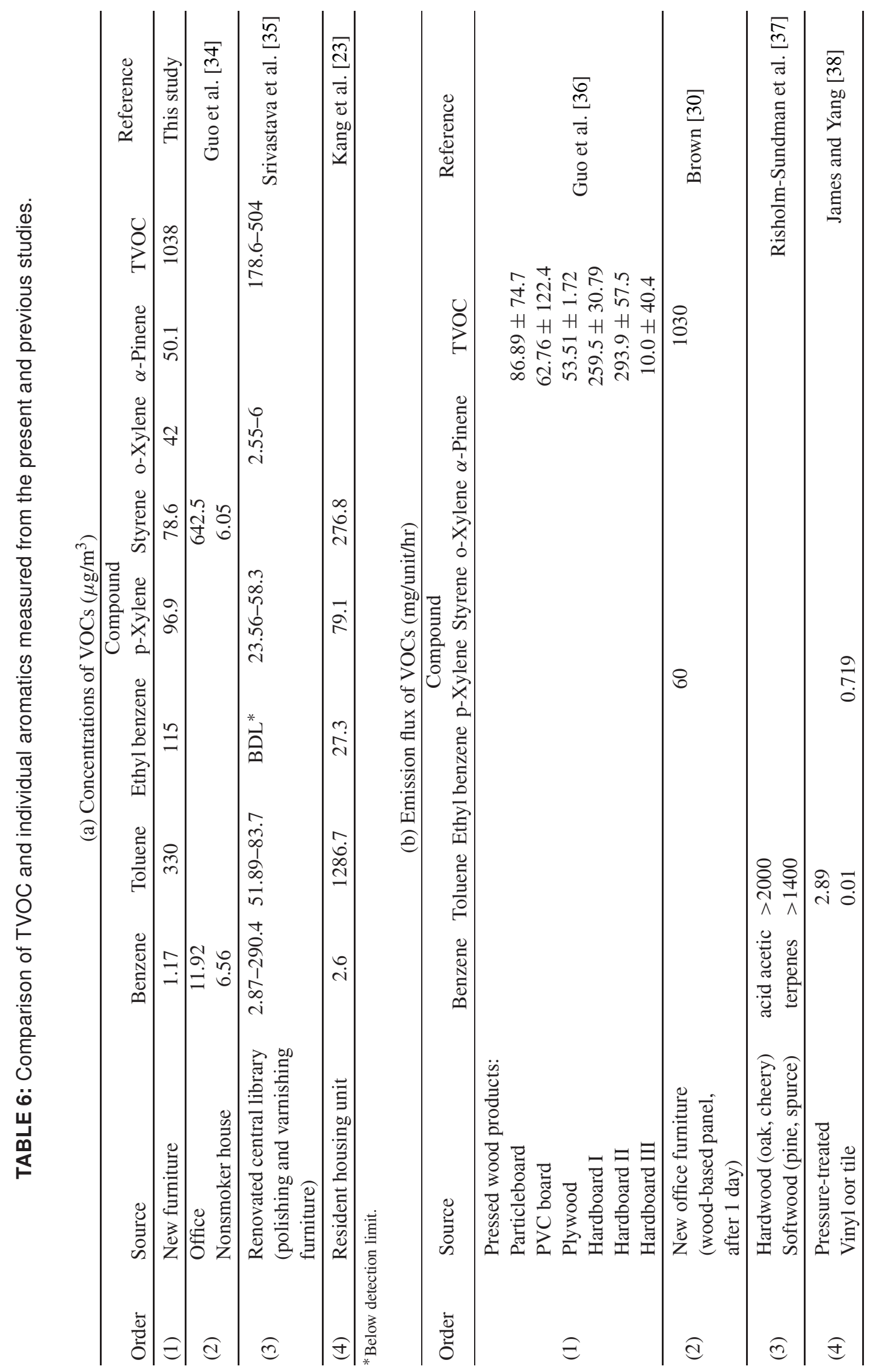


the following order: AR $>$ TER $>$ CBN $>$ others $>$ PR $>$ HOL $>$ HPR. The relative dominance of toluene and $\alpha$-pinene among all individual components emitted from diverse testing samples is suspected to be caused by PU leather and foam, while those made by others (MDF, HDF, PP, and coating agents (PVC and LPM)) were not distinctive enough to influence the overall emission rates. It is thus necessary to understand that signatures of VOC emissions can exist in a highly delicate manner between different kinds of furniture. In light of the human health risks associated with VOCs pollution in indoor environments, a better knowledge of emissions from diverse furniture types, as investigated in a limited scale in this study, are greatly needed to properly maintain a healthy indoor environment for human being.

\section{ACKNOWLEDGMENT}

This study was supported by a National Research Foundation of Korea (NRF) grant funded by the Ministry of Education, Science and Technology (MEST) (no. 2009-0093848). The second author also acknowledges the partial support from Korea University.

\section{REFERENCES}

[1] W. F. Hunt, R. B. Faoro, and W. Freas, "Interim data base for state and local air toxic volatile organic chemical measurements," Tech. Rep. PB-87-168779/XAB; EPA-450/4-86/012, 1986, Medium: X; Size.

[2] B. N. Tam and C. M. Neumann, "A human health assessment of hazardous air pollutants in Portland, OR," Journal of Environmental Management, vol. 73, no. 2, pp. 131-145, 2004.

[3] K. W. You, Y. S. Ge, B. Hu et al., "Measurement of in-vehicle volatile organic compounds under static conditions," Journal of Environmental Sciences, vol. 19, no. 10, pp. 1208-1213, 2007.

[4] K. Matsumoto, K. Matsumoto, R. Mizuno, and M. Igawa, "Volatile organic compounds in ambient aerosols," Atmospheric Research, vol. 97, no. 1-2, pp. 124-128, 2010.

[5] N. J. Lawryk and C. P. Weisel, "Concentrations of volatile organic compounds in the passenger compartments of automobiles," Environmental Science and Technology, vol. 30, no. 3, pp. 810-816, 1996.

[6] P. L. Leung and R. M. Harrison, "Roadside and in-vehicle concentrations of monoaromatic hydrocarbons," Atmospheric Environment, vol. 33, no. 2, pp. 191-204, 1999.

[7] A. Colombo and M. de Bortoli, "Comparison of models used to estimate parameters of organic emissions from materials tested in small environmental chambers," Indoor Air, vol. 2, no. 1, pp. 49-57, 1992.

[8] S. S. Cox, D. Zhao, and J. C. Little, "Measuring partition and diffusion coefficients for volatile organic compounds in vinyl flooring," Atmospheric Environment, vol. 35, no. 22, pp. 3823-3830, 2001.

[9] S. Kim, J. A. Kim, J. Y. An, H. J. Kim, and S. J. Moon, "Development of a test method using a VOC analyzer to measure VOC emission from adhesives for building materials," Journal of Adhesion Science and Technology, vol. 20, no. 15, pp. 1783-1799, 2006.

[10] T. Salthammer, F. Fuhrmann, V. Kühn, E. Massold, and N. Schulz, "Assessment of building products by chemical and sensory tests," Beurteilung von Bauprodukten Durch Chemische und Sensorische Prüfungen, vol. 64, no. 3, pp. 111-117, 2004.

[11] O. Wilke, O. Jann, and D. Brödner, "VOC- and SVOC-emissions from adhesives, floor coverings and complete floor structures," Indoor Air, vol. 14, no. 8, pp. 98-107, 2004.

[12] P. Wolkoff, "Are we measuring the relevant indoor pollutants?" Indoor Air, vol. 7, no. 2, pp. 92-106, 1997.

[13] T. Salthammer, A. Schwarz, and F. Fuhrmann, "Emission of reactive compounds and secondary products from wood-based furniture coatings," Atmospheric Environment, vol. 33, no. 1, pp. 75-84, 1998.

[14] P. Carrer, M. Maroni, D. Alcini, and D. Cavallo, "Allergens in indoor air: environmental assessment and health effects," Science of the Total Environment, vol. 270, no. 1-3, pp. 33-42, 2001.

[15] F. Fung and R. F. Clark, "Health effects of mycotoxins: a toxicological overview," Journal of ToxicologyClinical Toxicology, vol. 42, no. 2, pp. 217-234, 2004.

[16] J. A. Bernstein, N. Alexis, H. Bacchus et al., "The health effects of nonindustrial indoor air pollution," Journal of Allergy and Clinical Immunology, vol. 121, no. 3, pp. 585-591, 2008. 
[17] F. Haghighat and Y. Zhang, "Modelling of emission of volatile organic compounds from building materialsestimation of gas-phase mass transfer coefficient," Building and Environment, vol. 34, no. 4, pp. 377-389, 1999.

[18] L. E. Sparks, Z. Guo, J. C. Chang, and B. A. Tichenor, "Volatile organic compound emissions from latex paint -part 1. Chamber experiments and source model development," Indoor Air, vol. 9, no. 1, pp. 10-17, 1999.

[19] S. S. Cox, J. C. Little, and A. T. Hodgson, "Predicting the emission rate of volatile organic compounds from vinyl flooring," Environmental Science and Technology, vol. 36, no. 4, pp. 709-714, 2002.

[20] A. Afshari, B. Lundgren, and L. E. Ekberg, "Comparison of three small chamber test methods for the measurement of VOC emission rates from paint," Indoor Air, vol. 13, no. 2, pp. 156-165, 2003.

[21] Y. Xu and Y. Zhang, "A general model for analyzing single surface VOC emission characteristics from building materials and its application," Atmospheric Environment, vol. 38, no. 1, pp. 113-119, 2004.

[22] S. Kim, J. A. Kim, H. J. Kim, and S. D. Kim, "Determination of formaldehyde and TVOC emission factor from wood-based composites by small chamber method," Polymer Testing, vol. 25, no. 5, pp. 605-614, 2006.

[23] D. H. Kang, D. H. Choi, S. M. Lee, M. S. Yeo, and K. W. Kim, "Effect of bake-out on reducing VOC emissions and concentrations in a residential housing unit with a radiant floor heating system," Building and Environment, vol. 45, no. 8, pp. 1816-1825, 2010.

[24] S. C. Lee, S. Lam, and H. K. Fai, "Characterization of VOCs, ozone, and PM10 emissions from office equipment in an environmental chamber," Building and Environment, vol. 36, no. 7, pp. 837-842, 2001.

[25] Agency for Toxic Substances and Disease Registry (ATSDR), "Toxicological Profile for Toluene," 2000.

[26] United States Environment Protection Agency (US EPA), "Benzene (CASRN 71-43-2)," 2003, http://www. epa.gov/iris/subst/0276.htm.

[27] H. Guo and F. Murray, "Determination of total volatile organic compound emissions from furniture polishes," Clean Products and Processes, vol. 3, no. 1, pp. 42-48, 2001.

[28] Ministry of Environment, Republic of Korea (KMOE), "Announcement of in-door air quality management Act," 2006, http://eng.me.go.kr/board.do?method=view\&bbsCode=new_news\&docSeq=7843.

[29] Ministry of Environment, Republic of Korea (KMOE), "Management Measures of Indoor Air Pollutants," 2007, http://eng.me.go.kr/content.do?method=moveContent\&menuCode=pol_hnc_liv_ind_pollutants.

[30] S. K. Brown, "Chamber assessment of formaldehyde and VOC emissions from wood-based panels," Indoor Air, vol. 9, no. 3, pp. 209-215, 1999.

[31] X. Yang, Q. Chen, J. S. Zhang, R. Magee, J. Zeng, and C. Y. Shaw, "Numerical simulation of VOC emissions from dry materials," Building and Environment, vol. 36, no. 10, pp. 1099-1107, 2001.

[32] M. D. Koontz and M. L. Hoag, "Volatile organic compound emissions from particleboard and medium density fibreboard," in Measuring and Controlling Volatile Organic Compound and Particulate Emissions from Wood Processing Operations and Wood-Based Products, pp. 76-87, Forest Products Society, Madison, Wis, USA, 1995.

[33] R. B. Jørgensen, O. Bjørseth, and B. Malvik, "Chamber testing of adsorption of volatile organic compounds (VOCs) on material surfaces," Indoor Air, vol. 9, no. 1, pp. 2-9, 1999.

[34] H. Guo, S. C. Lee, L. Y. Chan, and W. M. Li, "Risk assessment of exposure to volatile organic compounds in different indoor environments," Environmental Research, vol. 94, no. 1, pp. 57-66, 2004.

[35] P. K. Srivastava, G. G. Pandit, S. Sharma, and A. M. M. Rao, "Volatile organic compounds in indoor environments in Mumbai, India," Science of the Total Environment, vol. 255, no. 1-3, pp. 161-168, 2000.

[36] H. Guo, F. Murray, and S. C. Lee, "Emissions of total volatile organic compounds from pressed wood products in an environmental chamber," Building and Environment, vol. 37, no. 11, pp. 1117-1126, 2002.

[37] M. Risholm-Sundman, M. Lundgren, E. Vestin, and P. Herder, "Emissions of acetic acid and other volatile organic compounds from different species of solid wood," European Journal of Wood and Wood Products, vol. 56, no. 2, pp. 125-129, 1998.

[38] J. P. James and X. Yang, "Emissions of volatile organic compounds from several green and non-green building materials: a comparison," Indoor and Built Environment, vol. 14, no. 1, pp. 69-74, 2005.

[39] N. Hudson and G. A. Ayoko, "Odour sampling 1: physical chemistry considerations," Bioresource Technology, vol. 99, no. 10, pp. 3982-3992, 2008.

[40] V. Blanes-Vidal, M. N. Hansen, A. P. S. Adamsen, A. Feilberg, S. O. Petersen, and B. B. Jensen, "Characterization of odor released during handling of swine slurry: part II. Effect of production type, storage and physicochemical characteristics of the slurry," Atmospheric Environment, vol. 43, no. 18, pp. 3006-3014, 2009. 
This article should be cited as follows:

Duy Xuan Ho, Ki-Hyun Kim, Jong Ryeul Sohn, Youn Hee Oh, and Ji-Won Ahn, "Emission Rates of Volatile Organic Compounds Released from Newly Produced Household Furniture Products Using a Large-Scale Chamber Testing Method," TheScientificWorldJOURNAL, vol. 11, pp. 1597-1622, 2011. 


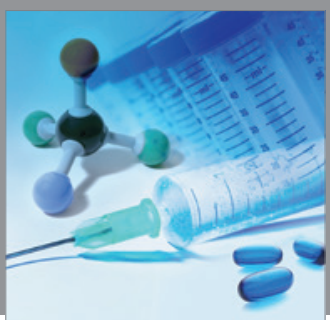

International Journal of

Medicinal Chemistry

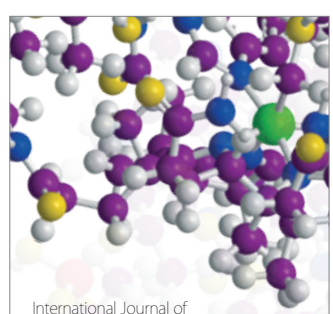

Carbohydrate Chemistry

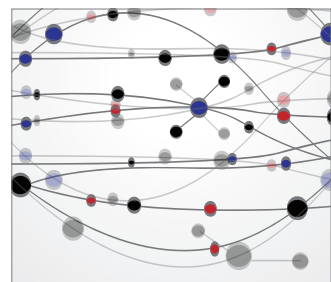

The Scientific World Journal
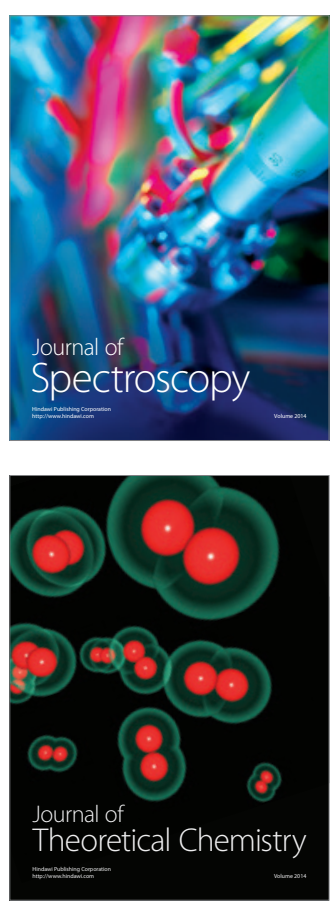
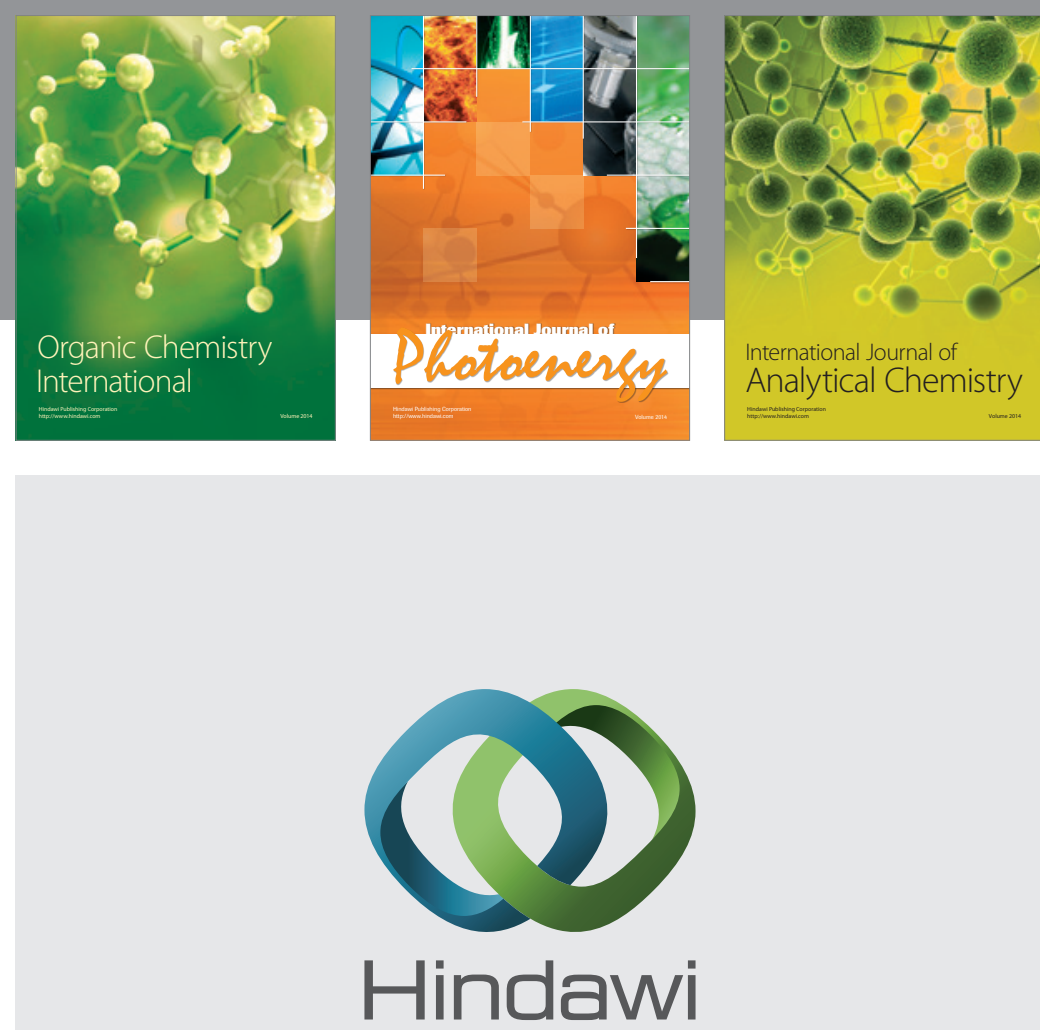

Submit your manuscripts at

http://www.hindawi.com
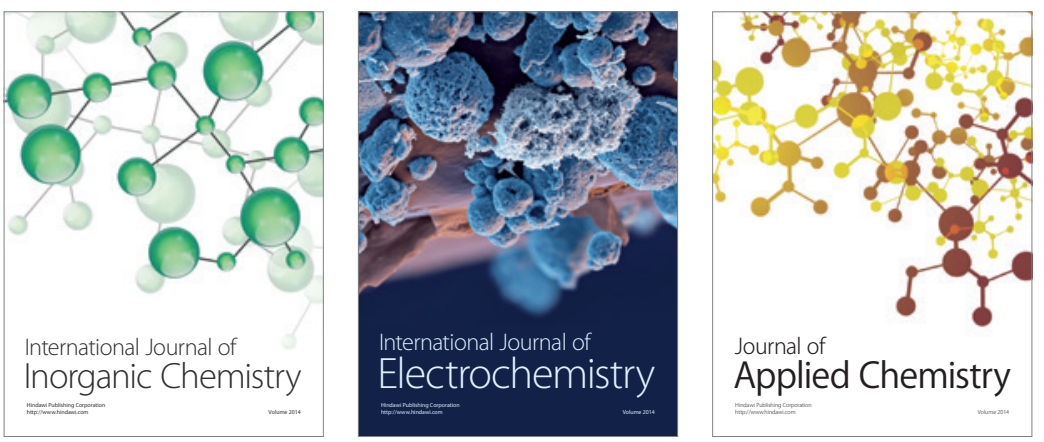

Journal of

Applied Chemistry
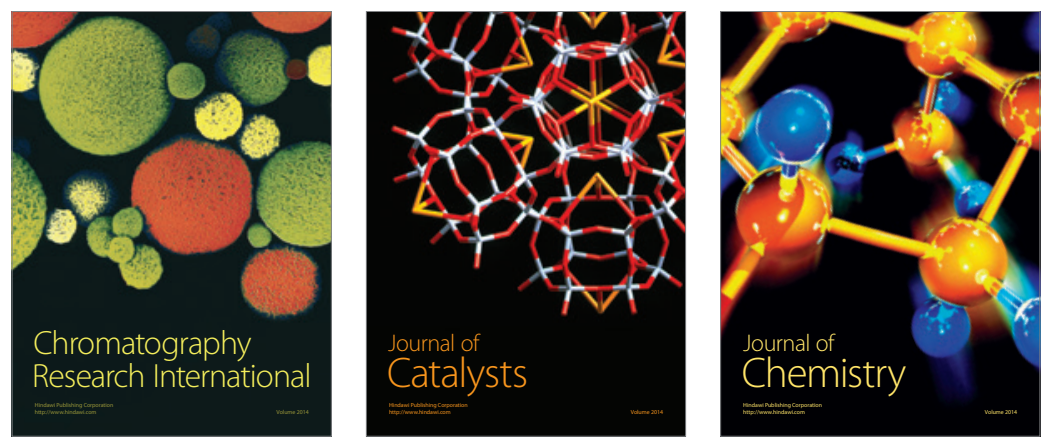
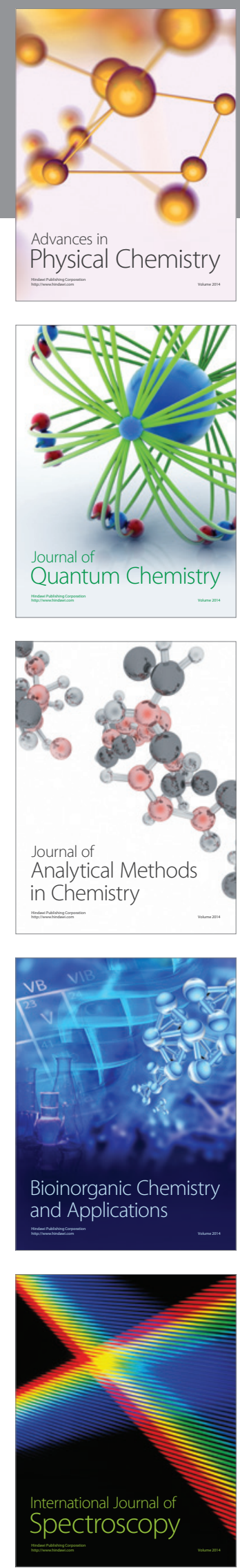